
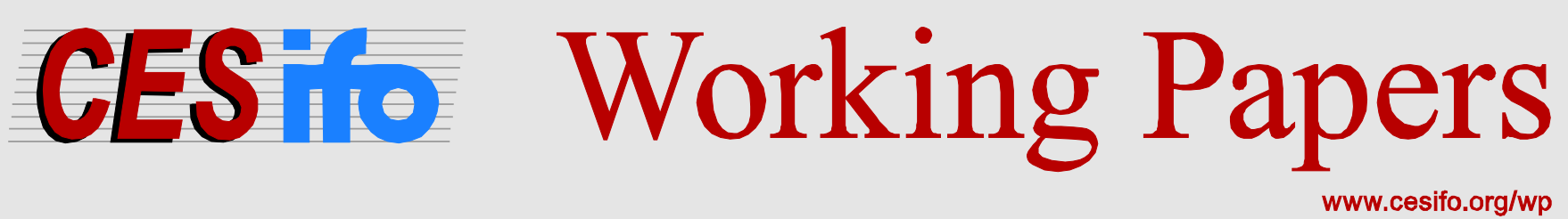

\title{
The Effects of Size-Based Regulation on Small Firms: Evidence from VAT Threshold
}

\author{
Jarkko Harju \\ Tuomas Matikka \\ Timo Rauhanen
}

CESIFO WORKING PAPER NO. 6115

CATEgORY 1: PUBlic FinANCE

SEPTEMBER 2016

An electronic version of the paper may be downloaded

- from the SSRN website:

- from the RePEc website:

- from the CESifo website:

WWW.SSRN.com

www.RePEc.org

www.CESifo-group.org/wp 


\title{
The Effects of Size-Based Regulation on Small Firms: Evidence from VAT Threshold
}

\begin{abstract}
There is only limited evidence of how small firms respond to size-based regulations applied in various countries. We study this question by examining the value-added tax (VAT) threshold in Finland. We find sizable bunching of firms in the sales distribution just below the exemption threshold, implying that firms actively avoid VAT liability. We utilize variation in both the VAT rate and reporting requirements to provide compelling evidence that the response is caused by the compliance costs of VAT reporting rather than the level of the tax rate. In addition, we find that compliance costs hinder the growth of small firms.
\end{abstract}

JEL-Codes: D220, H250, H320, L110.

Keywords: firm behavior, compliance costs, value-added tax.

\author{
Jarkko Harju \\ VATT Institute for Economic Research \\ Helsinki / Finland \\ jarkko.harju@vatt.fi
}

\author{
Tuomas Matikka \\ VATT Institute for Economic Research \\ Helsinki / Finland \\ tuomas.matikka@vatt.fi
}

\author{
Timo Rauhanen \\ VATT Institute for Economic Research \\ Helsinki / Finland \\ timo.rauhanen@vatt.fi
}

September 16, 2016

Many thanks to David Agrawal, Saku Aura, Youssef Benzarti, Leon Bettendorf, Raj Chetty, Ari Hyytinen, Tuomas Kosonen, Kaisa Kotakorpi, Tomi Kyyrä, Li Liu, Teemu Lyytikäinen, Simone Moriconi, Andreas Peichl, Emmanuel Saez, Matti Sarvimäki, Joel Slemrod and Floris Zoutman for their useful comments and discussion. We also thank the participants at many conferences and seminars for their helpful comments. Also, we thank the Finnish Tax Administration and the Swedish Tax Agency for data access. All remaining errors are our own. 


\section{Introduction}

Various types of size-based regulations are commonly applied to firms. These rules are apparent in, for example, tax schedules, tax enforcement and accounting regulations, and health and safety standards. The main issue with these regulations is that they create incentives for firms to stay small. Such incentives are generally undesirable, as they can reduce growth and productivity (Garicano et al. 2016; Best et al. 2015; Hsieh and Klenow 2009; Besley and Burgess 2004; Carroll et al. 2001) and distort the firm-size distribution (Gourio and Roys 2014; Dharmapala et al. 2011; Guner et al. 2008). Despite their common occurrence, there is little empirical evidence of how size-based rules affect the behavior of firms and their owners, and which types of thresholds actually cause the largest distortions. This knowledge is particularly relevant for small and young firms, who are found to contribute significantly to overall growth and productivity (Haltiwanger et al. 2016; Criscuolo et al. 2014).

We exploit the value-added tax (VAT) threshold to provide evidence of the effects of a size-based rule on the behavior of small firms. In Finland, firms with less than 8,500 euros of annual sales are not required to report and remit VAT ${ }^{1}$ Therefore, both tax incentives (remitted VAT) and compliance costs (frequent filing of VAT reports, understanding the VAT system etc.) change at this threshold in a discontinuous manner, creating incentives for firms not to exceed the VAT threshold. Reforms in both the VAT rate and VAT reporting requirements allow us to study whether responses to the threshold are caused by tax incentives or compliance costs. In addition, we study the impact of the threshold on output growth of small firms and entrepreneurs.

This paper offers new, micro-level empirical evidence of how and why small firms respond to size-based regulation. From a policy perspective, it is crucial to know whether purely monetary incentives, such as tax rates, or compliance costs cause the potential distortions induced by such rules. This is the first study that distinguishes between the compliance cost and tax rate responses of small firms utilizing quasi-experimental variation, providing clear results on the underlying mechanisms behind firm responses. We find sizable bunching of firms in the sales distribution just below the threshold,

\footnotetext{
${ }^{1}$ VAT is a broadly based tax assessed on the value added to goods and services. VAT is a commonly applied form of consumption taxation in many countries. Most VAT systems include varying thresholds below which firms are exempt from remitting and reporting VAT. For example, in the EU countries, the VAT thresholds vary between 0-100,000 euros. Half of the EU countries apply thresholds below 25,000 euros, including e.g. Germany, Belgium and Denmark. In Finland, firms below the threshold can voluntarily register for VAT. For example, this can be beneficial for firms with a large share of business-to-business transactions or large start-up costs that are deductible from remitted VAT.
} 
implying that firms actively avoid VAT liability. We provide compelling evidence that the response is caused by the compliance costs of VAT reporting rather than the level of the tax rate.

In addition, we provide new evidence of the growth barriers of small firms. Knowledge of the factors that hinder growth among small and fledgling businesses is increasingly important, as the emergence of small service sector firms and entrepreneurs, such as Uber drivers and Airbnb suppliers, is likely to continue (see e.g. Zervas et al. (2016)). Therefore, it is particularly interesting to learn how a size-based threshold affects these types of firms, and which types of incentives are the most important. We find that the bunching behavior is very permanent, indicating that compliance costs hinder the growth of small firms. In particular, the negative growth effect is distinctive among low-income service sector entrepreneurs, but it reduced significantly when compliance costs were reduced.

We utilize high-quality tax register data on all Finnish firms and their owners for 2000-2013. We use the bunching methodology introduced by Saez (2010), and further developed by Chetty et al. (2011) and Kleven and Waseem (2013), to study whether the discontinuous change in incentives induces small firms not to exceed the VAT threshold. The bunching method utilizes the excess mass in the sales distribution at the threshold to infer the extent of the intensive margin behavioral response caused by it. A particular advantage of the bunching approach is that we obtain visually clear and convincing results on the effects of the threshold.

The VAT threshold in Finland is low, and thus it mainly affects very small firms and low-income entrepreneurs. In the data, $90 \%$ of the firms in the neighborhood of the threshold are single-owned entities, which implies that firm-level decisions typically reflect the choices and preferences of a single entrepreneur. Approximately 35\% of these small firms operate in the service sector, but the overall heterogeneity in the industry classification is considerable. Over $50 \%$ of the owners of small firms have low personal taxable income below 10,000 euros, and approximately $20 \%$ of owners have relevant personal income sources outside the firm (above 30,000 euros), indicating that the firm constitutes just one source of income for many individuals.

As our first result we observe that the VAT threshold causes a large and significant overall behavioral response. We find large excess mass of firms in the sales distribution just below the threshold, implying that small firms actively avoid VAT liability. Our results indicate that all types of owners and firms respond significantly. However, the 
behavioral effects are more pronounced among sole proprietors and service sector firms, which suggests that the distortions caused by the threshold are largest in these groups.

We utilize various sources of variation in tax incentives and compliance costs to provide evidence of the factors that cause small firms to avoid VAT registration. Before 2004, the average VAT rate increased sharply if a firm's sales exceeded the threshold. Firms above the threshold owed full VAT on all sales, including sales below the threshold. In 2004, Finland introduced a VAT relief scheme in which the average tax rate increases gradually above the threshold. For an example firm with sales of 10,000 euros and no tax-deductible expenses, the remitted VAT decreased from 2,200 euros to 250 euros after the reform, implying that the VAT relief system induced a drastic reduction in remitted VAT in the neighborhood of the threshold. In addition, Finland experimented with targeted VAT rate reductions for certain specific types of services, which we utilize in our analysis as a source of additional variation.

VAT reporting requirements changed in 2010 in two ways. Both of these changes reduced the compliance costs of VAT reporting among small firms. First, before 2010, firms needed to file a separate tax form in order to receive the VAT relief. After 2010, VAT relief can be obtained by simply ticking a box in the regular VAT form. Second, small firms with annual sales below 25,000 euros are required to file a VAT report annually, in contrast to monthly reporting before 2010 .

Surprisingly, we find that even considerable reductions in the VAT rate do not affect the extent of the bunching response. We do not find any changes in the observed behavior after the drastic drop in the VAT rate at the threshold in 2004, nor between similar industries that faced different changes in VAT rates over time. In contrast, the excess mass below the threshold decreased sharply when compliance costs were reduced in 2010 .

Our results strongly indicate that compliance costs are the key factor in explaining the observed behavior. This implies that decreasing compliance costs by, for example, simplifying or reducing reporting procedures can alleviate the distortions caused by size-based regulation among small firms. Most previous public finance studies focus on analyzing the tax rate elasticity, that is, how much a relative change in the tax rate affects the outcome variable of interest (see e.g. Best et al. (2015) and Devereux et al. (2014)), ignoring the potential effects of compliance costs. Our results highlight that interpreting the behavioral response as being caused solely by the VAT rate would largely overestimate the significance of tax incentives. If we interpret the entire response as stemming from tax incentives, we find that the implied local tax rate elasticity jumped discretely 
from 0.2 to 0.9 in 2004 when the VAT rate at the threshold was significantly reduced but no changes in bunching behavior was observed. It is implausible that such a sudden hike would have occurred in the underlying average tax elasticity of entrepreneurs.

Size-based thresholds typically create incentives for firms to stay small, which could induce negative growth effects and cause significant long-run efficiency losses (see e.g. Guner et al. (2008), and Gourio and Roys (2014)). In the Finnish context, the VAT threshold could hinder the growth of small businesses if firms avoid exceeding the threshold for a prolonged period of time. The panel structure of the data allows us to follow firms over time, and thus examine the effects of the threshold on growth. In addition, we compare small Finnish firms in labor-intensive industries to similar firms in Sweden, a neighboring country of Finland. There is no VAT threshold in Sweden, and thus Swedish firms represent an intuitive benchmark for analyzing the growth effects of the Finnish threshold. Despite the different VAT threshold policy, Finland and Sweden are very similar in terms of the VAT system (e.g. tax rates and reporting practices), the business tax structure and the overall institutional and cultural framework.

Our results show that a significant share of firms avoid exceeding the threshold for many consecutive years. Our evidence indicates that this negative growth effect is focused on low-income service sector entrepreneurs. In addition, we find smaller negative growth effects after the compliance cost reform, highlighting the detrimental role of compliance costs. Moreover, a comparison of Finnish and Swedish firms in labor-intensive industries supports the overall conclusion that the VAT threshold has notable effects on growth. In 2005-2013, the average annual growth rate of Finnish firms just below the threshold was zero, while comparable Swedish firms increased their annual sales by 10-15\%. In addition, we find that the exit rates of firms increase above the threshold in Finland, which suggests that the threshold also affects the extensive margin decisions of entrepreneurs.

We also examine whether the behavioral responses are driven by tax avoidance, tax evasion or the real output margin. We find no systematic tax avoidance in terms of owners splitting larger firms into smaller entities. In addition, we find no clear support for underreporting of sales, which implies that tax evasion responses are not explaining the results. Therefore, we interpret that firms respond via changes in real output and economic activity. Combined with the evidence of negative growth effects, this suggests that the efficiency effects of compliance costs can be notable (see e.g. Slemrod (1992) for a discussion of the welfare effects of different types of responses).

This paper contributes to several branches of literature. Our results add to the scarce 
empirical literature examining the effects of different size-based rules and regulations on firm behavior. Best et al. (2015) observe that firms bunch sharply at the kink point that separates the turnover and profit tax regimes in Pakistan. They utilize variation in incentives over time and across firms to show that, unlike our results, the observed behavior is mainly driven by tax evasion. Gourio and Roys (2014) and Garicano et al. (2016) examine the effects of an employee threshold (50 pers.) in France above which many types of costs and regulations are increased and tightened (e.g. the payroll tax rate and firing costs). Both of these papers find that this threshold clearly affects the firm-size distribution and the productivity of firms. Almunia and Lopez-Rodriguez (2016) study the responses to a tax enforcement threshold using Spanish firm data. They find that large firms avoid exceeding the stricter enforcement by bunching just below the threshold, and observe that the effect is driven by evasion responses. In contrast, they do not find any bunching at a corporate tax rate kink point, thus providing suggestive evidence that firms respond more to regulatory thresholds compared to discontinuous changes in tax incentives.

Despite the general application of VAT thresholds, only a few previous papers study the effects of these thresholds. The theoretical literature has characterized the rules for an optimal VAT threshold. Keen and Mintz (2004) and Kanbur and Keen (2014) show that the optimal VAT threshold depends on, for example, administrative and compliance costs, and the extent to which firms respond to the threshold. We contribute to this literature by applying actual quasi-experimental estimates on behavioral responses to evaluate the optimal threshold. We find that the optimal threshold in Finland is approximately 40,000 euros, which is four times larger than the current threshold.

The existing empirical literature has focused on VAT thresholds in relation to larger firms. Onji (2009) was the first to detect clear effects of a VAT threshold (approx. 3,3 million US dollars) on the distribution of firms in Japan. He shows that large Japanese firms reacted to the introduction of a VAT threshold by splitting into smaller entities, reflecting clear tax avoidance behavior. Liu and Lockwood (2015) show that firms in the UK bunch actively at the relatively large VAT threshold (100,000 euros). Also, Waseem (2015) observes a clustering of firms at the VAT threshold in Pakistan (42,000e), and Boonzaaier et al. (2016) in South Africa (63,000e). In contrast, Asatryan and Peichl (2016) find no responses to the VAT threshold in Armenia (150,000e), but find that firms respond to other regulative thresholds. We contribute to this literature by carefully examining the mechanisms behind the observed responses, and by analyzing the effects 
of the threshold among small firms.

Furthermore, our paper adds to the literature on the costs related to reporting taxes and understanding the tax code. For example, Chetty et al. (2009) show that the salience of sales tax rates is an important element in explaining behavioral responses among consumers. Benzarti (2016) studies the amount of hassle costs related to tax filing using register data on US income tax returns. He finds that these costs, approximately 650 US dollars on average, are much larger than previous estimates suggest. We contribute to this literature by showing that compliance costs are also highly relevant for small firms and entrepreneurs, and by estimating the magnitude of compliance costs for entrepreneurs using quasi-experimental variation and local non-linear estimation methods. We estimate that the annual compliance cost of VAT reporting for small firms is approximately 1,600 euros.

Finally, we contribute to the literature applying the bunching method to analyze the behavioral responses to income tax rate discontinuities among entrepreneurs. Devereux et al. (2014) find that small corporations in the UK respond sharply to a jump in the corporate income tax rate. Saez (2010), Chetty et al. (2011) and Bastani and Selin (2014) find that entrepreneurs in particular tend to respond actively to discontinuous jumps in their personal marginal income tax rates in the US, Denmark and Sweden, respectively. Supporting these results, the vast literature on taxable income responses to marginal income tax rates shows that entrepreneurs are particularly responsive, but the responses can be typically explained by tax avoidance behavior (see a survey by Saez et al. (2012), and Harju and Matikka (2016) for evidence for Finland). In contrast to this literature, we find no evidence of avoidance or underreporting, which implies that small firms respond by adjusting their true output. This is also consistent with the notion that low-income entrepreneurs and sole proprietors have more limited opportunities for avoidance, compared to high-income owners of corporations.

This paper proceeds as follows: Section 2 describes the VAT threshold in Finland, the conceptual bunching methodology and estimation strategy. Section 3 describes the data. Section 4 presents the results, and Section 5 concludes the study. 


\section{Institutions and methodology}

\section{$2.1 \quad$ Value-added taxation}

Most developed countries use value-added tax (VAT) as their primary consumption tax system. VAT is usually a broadly based tax assessed on the value added to goods and services. The amount of value added is calculated by subtracting the amount of externally purchased goods and services from the value of goods and services sold.

The VAT assessment process is the following: each trader in the chain of supply (from manufacturers to retailers) charges VAT on their sales. Individual firms are entitled to deduct the VAT paid on purchases from this amount. VAT is remitted to the tax authorities by the seller of the goods and services.

VAT is an important source of tax revenue in many countries. In Finland, VAT accounts for approximately one third of all tax revenue. Among OECD countries, almost one fifth of tax revenue is collected from VAT. However, the variation in VAT revenue is large across countries.

Finland, as a member of the European Union (EU), applies the general EU VAT legislation (European Commission (2006a)). All members of the EU apply a standard VAT rate of at least $15 \%$. The EU allows member countries to use a maximum of two reduced VAT rates for specific products and services, such as food and pharmaceuticals.

The standard VAT rate in Finland is $24 \%$ in 2016. The standard rate applies to most goods and services. Finland uses two reduced VAT rates: a 14\% rate is applied to e.g. food and restaurant services, and $10 \%$ is applied to e.g. books and pharmaceuticals. ${ }^{2}$

Some goods and services are exempt from VAT. These include financial and insurance activities, letting and operation of dwellings, education, health services and social work activities. Firms that sell solely these goods or services are not liable to remit VAT in Finland.

Moreover, EU legislation allows member states to apply reduced VAT rates to certain labor-intensive industries (European Commission (2006b)). Finland experimented with a special reduced VAT rate for hairdresser services. In 2007-2011, the VAT rate for hairdressers was reduced from $22 \%$ to $8 \% .3$ However, other similar services, such as those offered in beauty salons, were not part of the experiment and thus not subject to the

\footnotetext{
${ }^{2}$ Until 2010, the standard VAT rate was $22 \%$ in Finland. The standard VAT rate was increased to $23 \%$ in 2010 , and to $24 \%$ in 2013 . The first reduced rate was $17 \%$ until 2009 . It was decreased to $12 \%$ in 2009, and increased to $13 \%$ in 2010 and to $14 \%$ in 2013 . The second reduced rate was $8 \%$ until 2010 , and it was increased to $9 \%$ in 2010 and to $10 \%$ in 2013 .

${ }^{3}$ Kosonen (2015) studies the incidence and efficiency implications of this reform.
} 
reduced VAT rate.

\section{$2.2 \quad$ VAT threshold}

In many VAT systems, firms with annual sales below a certain predetermined threshold are not required to remit VAT and report sales and purchases subject to VAT to the tax authority. Figure 1 shows these annual sales thresholds in the OECD countries in 2014. The figure highlights that the thresholds vary considerably across countries. While some countries levy VAT on all sales without a specified VAT threshold (e.g. Sweden and Turkey), some countries apply relatively high thresholds around 100,000 euros (e.g. Switzerland and the UK). A notable share of countries apply a relatively low income threshold between 0-20,000 euros of annual sales, including e.g. Germany and Canada.

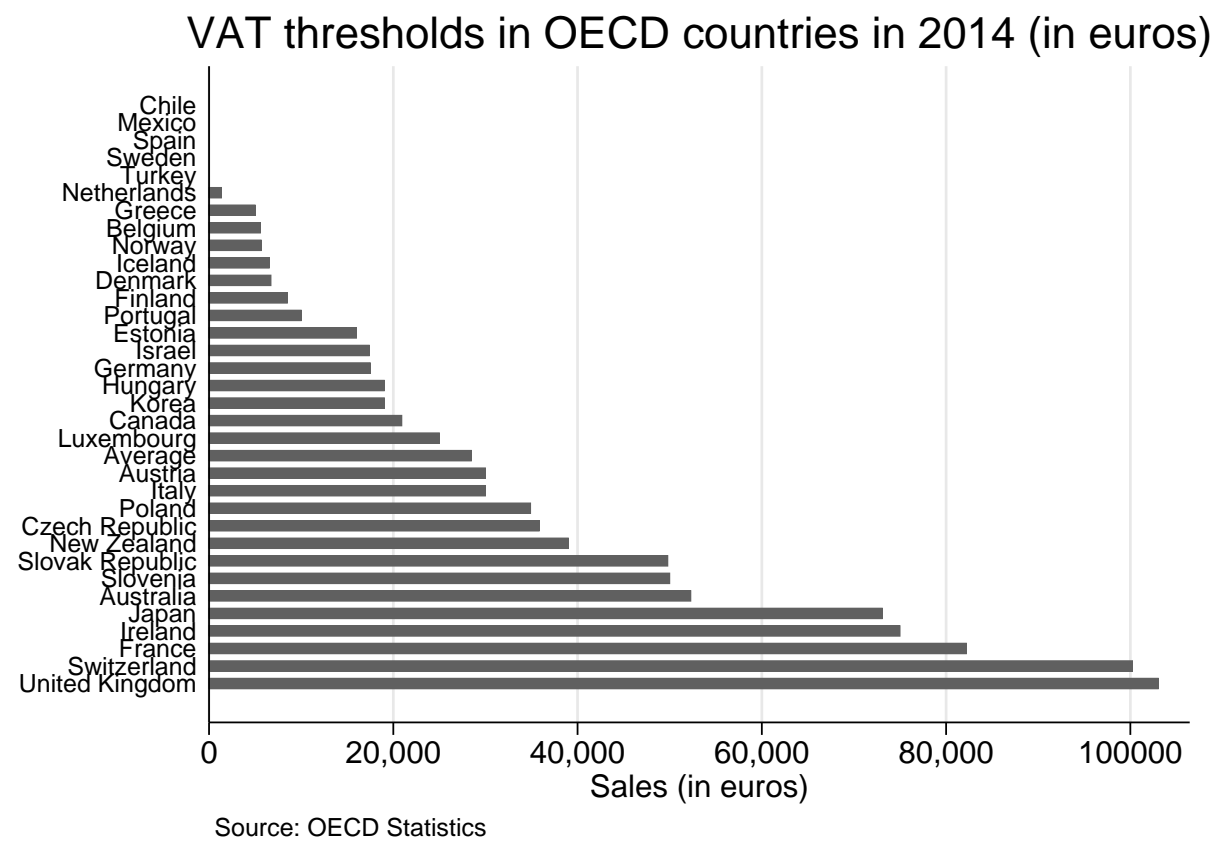

Figure 1: Annual sales thresholds of VAT registration in OECD countries in 2014 (in euros)

In Finland, the VAT threshold for firms was 8,500 euros of annual sales in 1995-2015. Note that on January 1st 2002, Finland replaced the Finnish mark with the euro as its official currency. Before 2002, the threshold was 50,000 Finnish marks, which is equivalent to 8,500 euros 4 Therefore, the threshold has remained constant from 1995 in nominal

\footnotetext{
${ }^{4}$ The official conversion rate was defined such that 1 euro is equivalent to 5.94573 marks. The euro was introduced as an account currency already in 1999, but euro banknotes and coins were circulated from the beginning of 2002. Therefore, the three years (1999-2002) were a transition period preparing for the euro (see e.g. http://ec.europa.eu/economy_finance/euro/countries/finland_en.htm).
} 
terms, although it was recently increased to 10,000 euros in 2016.

Even though small firms below the threshold are exempt from VAT, they need to report their overall sales for income tax purposes. Therefore, we have data on the annual sales of firms below the threshold, as this information is reported to the Tax Administration. Finally, the VAT threshold is not connected to other regulative rules, such as employer social security contribution rates or the right to claim individual-level unemployment benefits.

Tax incentives at the threshold. Next, we describe the main details related to the VAT threshold in Finland. We focus on recent policy changes that affected both the size of tax incentives and compliance costs. We utilize this variation in our main analysis when studying the mechanisms behind observed firm behavior.

Before 2004, firms that exceeded the threshold owed VAT on all value added. This included value added on sales below the threshold. Therefore, exceeding the VAT threshold created a notable jump in VAT liability and the average VAT rate.

In 2004, Finland changed its VAT system by introducing a VAT relief scheme. The VAT relief reduces remitted VAT such that the average VAT rate increases only gradually above the threshold, compared to a sharp discontinuous jump in the average VAT rate before. The VAT relief scheme was applied to firms with annual sales below 20,000 euros in 2004, and the relief was extended to firms with sales below 22,500 in 2005. This limit remained unchanged until 2016 when the upper limit of the relief region was extended to 30,000 .

Figure 2 shows VAT remittances in euros and average VAT rates for different levels of sales (in bins of 100 euros). The figure illustrates the introduction of the VAT relief region in 2004 and the post-2005 schedule in comparison to the pre-2004 period for a representative firm that is subject to the standard VAT rate. For illustrative purposes, the representative firm is assumed to have no deductible VAT on purchases, implying that the value added equals the sales of the firm.

The figure shows that the pre-reform system created a salient VAT notch, inducing a clear jump in remitted VAT and the average VAT rate from 0 to $22 \%$ at the threshold (the standard VAT rate in Finland was 22\% until July 1st 2010). After the reform, the notch was replaced by a VAT kink, implying gradually increasing remitted VAT and average VAT rate above the threshold. Within the VAT relief scheme, the gradually increasing average VAT rate implies an increasing marginal VAT rate above the threshold up to the point at which the average VAT rate equals $22 \%$. This leads to marginal VAT rates 
between $13-57 \%$ above the threshold within the relief region.

Figure 2 highlights the striking difference in tax incentives between the two VAT regimes. Consider a firm with annual sales of 10,000 euros, which thus exceeds the VAT threshold by 1,500 euros. Before 2004, the average VAT rate on all value added for this firm was $22 \%$. After 2004, the average VAT rate is around 2.5\%, which is over eight times less than before the reform. Thus, in terms of pure tax incentives, the reform induced a distinctive change at the threshold. However, as can be seen from the figure, the difference between the regimes decreases at larger sales levels, and disappears above the relief region.

Remitted VAT and average VAT rates before and after the reform
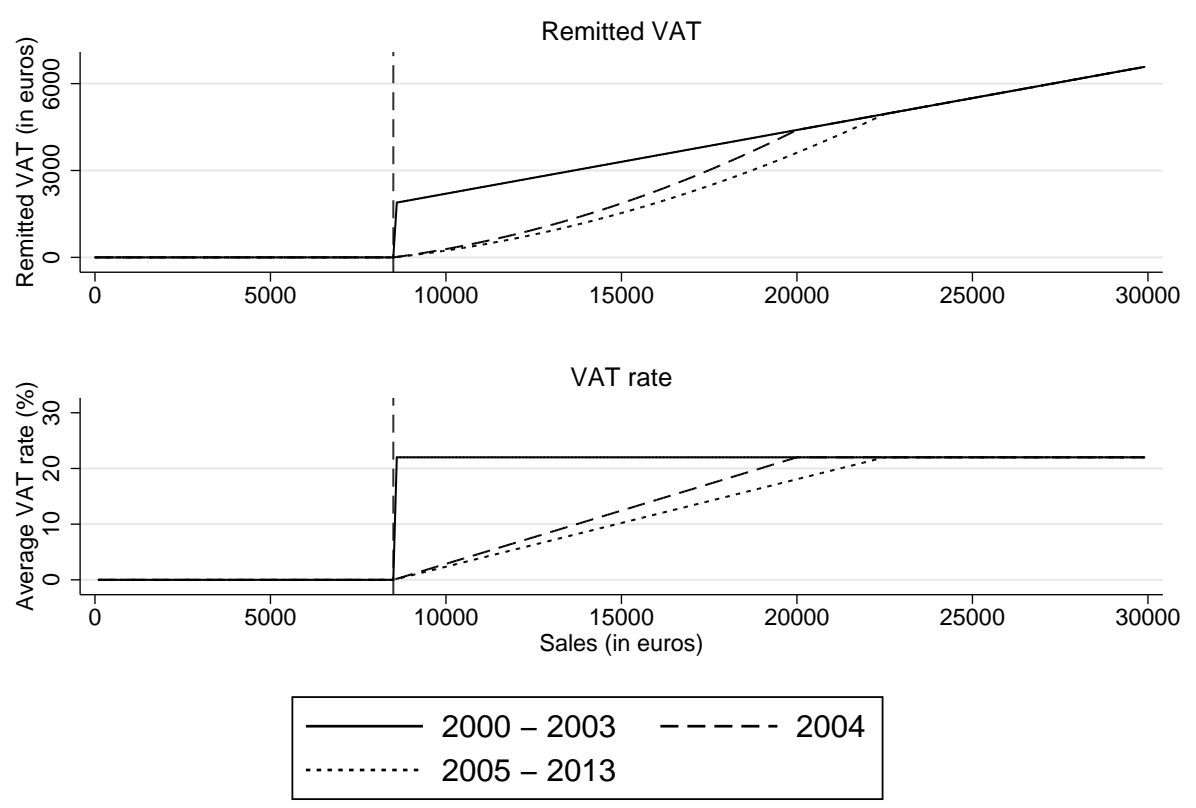

Figure 2: VAT remittance and average VAT rates for different levels of sales before and after the introduction of the VAT relief system in 2004

Compliance costs. In addition to remitted VAT, a firm faces other costs when exceeding the threshold. We refer to these as compliance costs. These include reporting and accounting costs related to VAT reporting, and cognitive costs of understanding the VAT system and applying the rules of VAT legislation.

Once a firm becomes liable for VAT, it needs to file separate periodic reports on sales and purchases subject to VAT. This procedure can be executed by the owner, or she can purchase an accounting service to conduct the VAT reporting for the firm. The reporting obligation covers sales at different VAT rates, input purchases, zero-rated sales, and imports and exports. Also, the firm is legally required to separate the share of VAT 
from the selling price in all receipts and invoices, which increases compliance costs. In addition, complex reporting procedures and detailed VAT rules can be difficult to learn and comprehend. Thus exceeding the threshold is likely to induce cognitive costs for the owners of small firms.

The compliance costs of VAT reporting changed in 2010. First, before 2010, firms needed to apply for the VAT relief using a separate tax form in order to be eligible for reduced VAT payments above the threshold (the VAT relief system is described above). From 2010 onward, firms can apply for VAT relief by simply ticking a box in the same periodic tax form they use to declare remitted VAT. This simplified procedure reduced the mechanical burden of filling out tax forms, and likely made the current VAT system more transparent.

Second, the frequency of the required VAT reports was changed. Before 2010, all firms needed to complete a VAT report on a monthly basis.5 After 2010, firms with annual sales below 25,000 euros are required to report their VAT annually.

Overall, both of these reforms reduced the compliance costs related to VAT registration for small firms. We utilize this variation to study whether reduced compliance costs affect the behavior of small firms close to the threshold.

Voluntary registration. Firms that do not exceed the VAT threshold can voluntarily register and remit VAT. There are logical reasons for registering even when it is not necessary. First, a firm can only deduct the VAT from its purchases if it is registered, and thus voluntary registration could be important for businesses that have, for example, large start-up costs. Second, firms below the threshold that have a large share of businessto-business sales have an increased incentive to register, as the VAT rebate is only granted for purchases from VAT registered firms. Thus some VAT registered firms might prefer other VAT registered firms in business-to-business transactions. Third, VAT registration can enhance the status of the firm and give the appearance that the firm is a large and trustworthy partner, and therefore increase business activity.

In contrast to non-registered firms, the VAT threshold induces smaller or no local changes in incentives for voluntarily registered firms. Compliance costs do not jump at the threshold for voluntarily registered firms as they are already reporting VAT. In addition, the VAT relief applies to voluntary registered firms below the threshold after 2004. This implies a jump in the marginal VAT rate at the threshold for voluntarily

\footnotetext{
${ }^{5}$ However, there were some minor exceptions to this rule. For example, for performing artists it was possible to declare VAT on a yearly basis.
} 
registered firms, but no discontinuous changes in compliance costs. In our analysis, we utilize voluntarily registered firms to provide additional evidence of the sole effect of the tax rate at the threshold 6

\subsection{Bunching at the VAT threshold}

A rapidly growing literature utilizes bunching around various points that create discontinuous changes in incentives to study the extent of behavioral responses and to recover structural parameters such as tax rate elasticities. The bunching approach, first introduced by Saez (2010), has been used in a wide range of applications, such as income taxes, social transfers and pricing policies, to offer evidence of intensive margin responses.7 The bunching methodology and recent literature is surveyed in Kleven (2015).

Intuitively, if a discontinuous change in VAT liability at the threshold affects the behavior of firms, we should find an excess mass of firms located just below the threshold in the sales distribution. As discussed above, exceeding the VAT threshold induces a discontinuous increase in both tax liability (remitted VAT) and compliance costs related to VAT reporting. Therefore, the threshold creates a notch in firms' choice set.

Figure 3 illustrates the effect of the VAT threshold on the behavior of firms with smooth and heterogeneous preferences over gross sales (effort of the owner/firm) and after-tax sales (profit before costs). For conceptual simplicity, we denote that firms respond to the threshold. However, a majority of small firms around the threshold are owned and managed by a single owner (almost $90 \%$ in our baseline sample). Thus we assume that the owner makes all the relevant firm-level decisions, and the effort of the owner largely contributes to the output of the firm.

First, we ignore compliance costs and discuss the incentives created solely by the change in the VAT rate. Panel I of figure 3 describes the budget set in the VAT notch system (pre-2004 system in Finland), which induced a clear discontinuous jump in remitted VAT at the threshold. The simplified tax function excluding other taxes than VAT is $T_{N}(s)=\left[\tau_{N}(s-z s)\right] \cdot \mathbf{1}\left(s>s^{*}\right)$, where $s^{*}$ is the VAT threshold and $\tau_{N}$ is the VAT rate. $z s$ denotes the linear function of tax-deductible purchases $z$ needed to generate $s$, where $0 \leq z<1$. In the figure, the VAT remitted below $s^{*}$ is denoted by $\triangle T\left(s^{*}\right)$, which creates the notch to the budget set.

\footnotetext{
${ }^{6}$ For voluntarily registered firms, there were no changes in the VAT rate nor compliance costs at the threshold before 2004, implying no incentives to remain below the threshold.

${ }^{7}$ In the end of Section 4.4, we also discuss the potential implications of the VAT threshold on extensive margin responses by examining the exit and entry rates of firms over the sales distribution.
} 
In the absence of the VAT threshold, firms locate themselves along the 45-degree budget line based on the preferences of their owners. When introducing the VAT notch, firms below or directly at the threshold (Type A firm in the figure) do not change their behavior. Type B firm represents a marginal bunching firm with sales $s^{*}+\triangle s^{N}$ in the absence of the threshold that is precisely indifferent between locating at $s^{*}$ or $s^{B}$. A fraction of firms with sales between $s^{*}$ and $s^{*}+\triangle s^{N}$ will move below the threshold, which creates an excess mass of firms at $s^{*}$ in the sales distribution.

Panel II displays bunching at the VAT kink system where tax liability increases gradually above the threshold (post-2003 system in Finland). The tax function is $T_{K}(s)=$ $\left[\left(s-s^{*}\right)-\left(z s-z s^{*}\right)\right] \tau_{k} \cdot \mathbf{1}\left(s>s^{*}\right)$, which implies that the firm remits VAT only on the value added exceeding $s^{*}$. Similarly as above, a fraction of firms located between $s^{*}$ and $s^{*}+\triangle s^{K}$ will bunch around the threshold. The principal difference between the notch and kink regimes is that the former creates notably larger incentives not to exceed the threshold.

Panel III of figure 3 introduces compliance costs to the VAT kink schedule. The extended tax function including compliance costs is $T_{C}(s)=\left\{\left[\left(s-s^{*}\right)-\left(z s-z s^{*}\right)\right] \tau_{k}+\right.$ $\left.\delta\left(s^{*}\right)\right\} \cdot \mathbf{1}\left(s>s^{*}\right)$, where $\delta\left(s^{*}\right)$ denotes the fixed compliance cost of VAT reporting. The assumption of fixed compliance costs is feasible, since the costs related to filling out VAT forms or understanding the VAT rules do not increase or decrease with sales close to $s^{*}$. These fixed compliance costs can vary across owners, thus creating different incentive changes at the threshold for different firms.

The introduction of fixed compliance costs creates an additional notch to the budget set, creating larger incentives to avoid exceeding the threshold. The effect of compliance costs is similar in the VAT notch schedule, where compliance costs increase the size of the notch in the budget set.

As discussed above, it is reasonable for some firms to register voluntarily for VAT. Consequently, as there are firms with no or only small incentives not to exceed the threshold, we are likely to observe a positive mass of firms also just above the VAT threshold in the sales distribution. In other words, the VAT threshold does not induce a region of dominated choice just above the threshold where no firms with standard preferences will locate, in comparison to an income tax notch often discussed in the bunching literature (Kleven 2015; Kleven and Waseem 2013).

Following this, Panel IV illustrates the theoretical sales distribution in the presence of the VAT threshold. The solid blue line denotes the observed sales distribution after 
the introduction of the VAT threshold. The red dashed line denotes the counterfactual distribution that would exist in the absence of the threshold. A fraction of firms originally located between $s^{*}$ and $s^{*}+\triangle s$ move below the threshold because of tax incentives and/or compliance costs. This behavior creates a spike in the distribution at $s^{*}$, and a missing mass in the distribution above it. Assuming heterogeneous preferences across different firms and no extensive margin responses, the observed density gradually approaches the counterfactual density above $s^{*}$ (see Kleven (2015)).
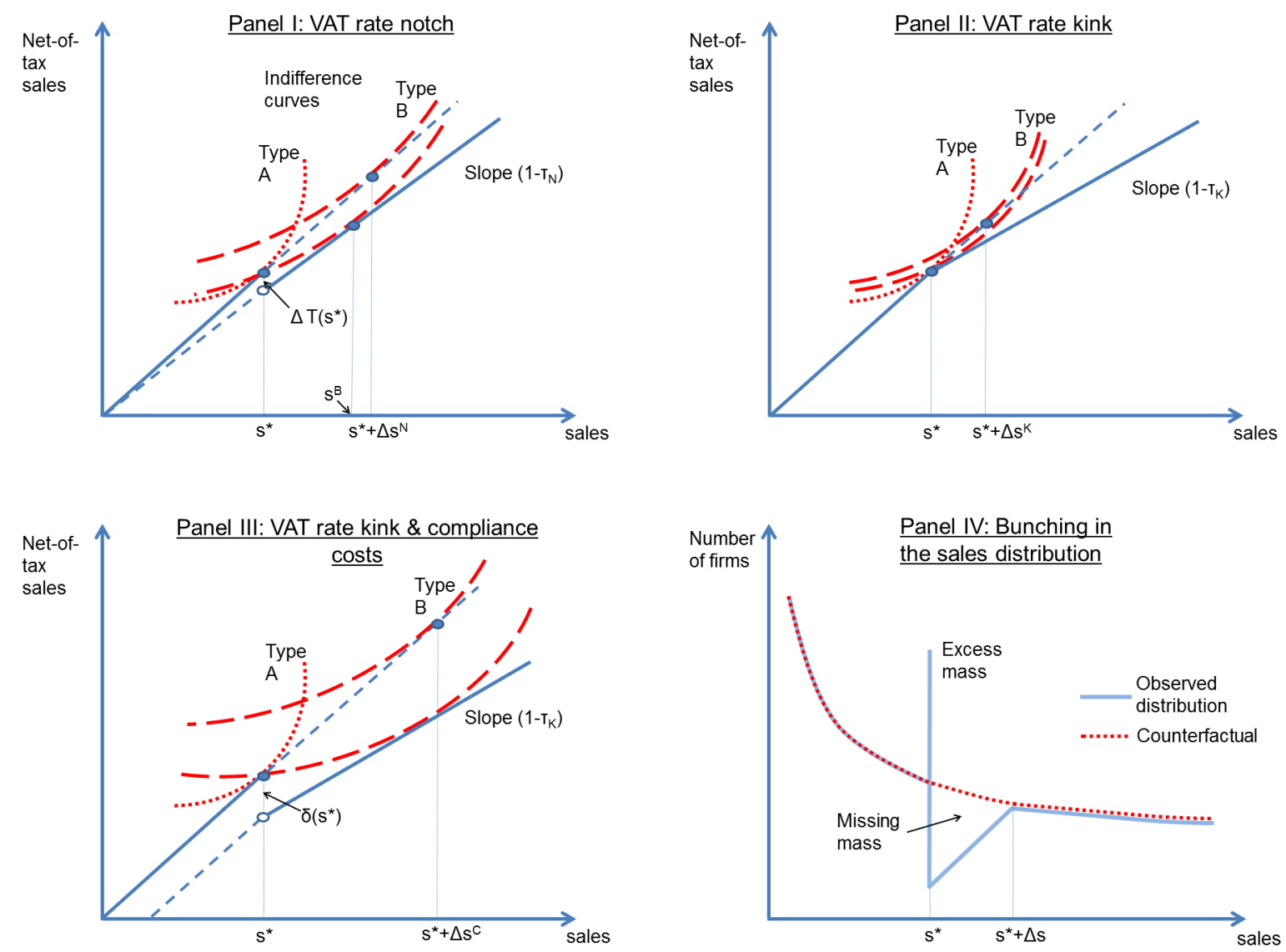

Figure 3: Bunching at the VAT rate notch (Panel I), VAT rate kink (Panel II), VAT rate kink with compliance costs (Panel III), and the theoretical sales distribution in the presence of bunching (Panel IV)

\subsection{Determinants of bunching behavior}

The behavioral response caused by the VAT threshold is estimated by relating the observed excess mass below the threshold to the counterfactual density. This bunching estimate includes responses to both tax incentives (the sales elasticity with respect to the VAT rate), and compliance costs. Therefore, the cross sectional bunching estimate is 
a function of two unobserved components: $\hat{b}=b\left(\tau, \delta, s^{*} ; e, \widetilde{\delta}\right)$, where $e$ is the underlying VAT rate elasticity and $\widetilde{\delta}$ denotes the responsiveness to compliance costs. The sales elasticity with respect to the VAT rate is expressed as $e=\left(\triangle s^{*} / s^{*}\right) /(\triangle \tau / \tau)$, where the sales response $\left(\triangle s^{*} / s^{*}\right)$ is related to the change in the VAT rate at the threshold $(\triangle \tau / \tau)$. We discuss the practical estimation of the excess mass and the elasticity parameter in detail in Section 2.5.

In our main analysis, we follow the approach in Best et al. (2015) and Gelber et al. (2015) $)^{8}$ and utilize variation in incentives over time to distinguish between different unobserved factors that affect the extent of the bunching behavior. We utilize quasiexperimental variation in both tax incentives and compliance costs to study whether the observed response to the threshold is caused by the VAT rate or compliance costs, or both. To do this, we estimate the amount of bunching at the threshold in different tax incentive and compliance cost regimes over time.

In the following, we assume that both tax incentives and compliance costs change at the threshold simultaneously. In the case of the VAT notch (2000-2003), the amount of bunching is given by $b^{N}\left(\tau_{N}, \delta, s^{*} ; e, \widetilde{\delta}\right)=\int_{s^{*}}^{s^{*}+\triangle s^{N}} h_{0}(s) d s \simeq h_{0}\left(s^{*}\right) \triangle s^{N}$, where $h_{0}\left(s^{*}\right)$ is the estimated counterfactual density, and $s^{*}+\triangle s^{N}$ denotes the marginal bunching firm. Similarly, in the VAT kink system (2004-2009), the amount of bunching is defined as $b^{K}\left(\tau_{K}, \delta, s^{*} ; e, \widetilde{\delta}\right)=\int_{s^{*}}^{s^{*}+\triangle s^{K}} h_{0}(s) d s$. After the compliance cost reform (2010-2013), the excess bunching is $b^{C}\left(\tau_{K}, \delta_{C}, s^{*} ; e, \widetilde{\delta}\right)=\int_{s^{*}}^{s^{*}+\triangle s^{C}} h_{0}(s) d s$, where $\delta_{C}<\delta$.

If the tax rate drives firms to avoid exceeding the threshold, we should observe that $\hat{b}^{N}\left(\tau_{N}, \delta, s^{*} ; e, \widetilde{\delta}\right)>\hat{b}^{K}\left(\tau_{K}, \delta, s^{*} ; e, \widetilde{\delta}\right)$. In other words, there would always be more bunching in the notch schedule compared to the kink regime if the VAT rate drives the response. This hypothesis follows from assuming that the underlying tax rate elasticity remains constant over time. Assuming $b^{N}>b^{K}$ is feasible as long as the marginal buncher firm is located within the VAT relief region (below 22,500 euros) in the absence of the threshold. In this case, $T_{K}\left(s^{*}+\triangle s^{N}\right)<T_{N}\left(s^{*}+\triangle s^{N}\right)$ by definition, because the remitted VAT is smaller for the marginal buncher at a given point in the sales distribution above $s^{*}$ (see figure 2 above).

If compliance costs affect firm responses, we should observe that $\hat{b}^{K}\left(\tau_{K}, \delta, s^{*} ; e, \widetilde{\delta}\right)>$ $\hat{b}^{C}\left(\tau_{K}, \delta_{C}, s^{*} ; e, \widetilde{\delta}\right)$. This follows from the fact that the compliance costs are smaller after the 2010 reform $\left(\delta_{C}<\delta\right)$. Thus the overall incentives to avoid the VAT liability are

\footnotetext{
${ }^{8}$ Best et al. (2015) utilize changes in the location of the turnover/profit tax threshold over time in Pakistan to infer whether the observed response is caused by evasion or real responses. Gelber et al. (2015) utilize changes in the size of the kink created by the Social Security Annual Earnings Test (AET) in the US to distinguish between individual adjustment frictions and the structural earnings elasticity.
} 
smaller while the underlying responsiveness to compliance costs is assumed to remain constant.

Our testable hypotheses are therefore the following: if tax incentives fully drive the response, we should observe that the excess mass at the threshold decreases after the VAT relief reform by the full amount implied by the VAT rate elasticity. If the change in excess mass is smaller than that but still significant, we can deduce that both tax incentives and compliance costs explain the observed responses. If tax incentives induce no responses, we should find that $\hat{b}^{N} \approx \hat{b}^{K}$. This would indicate that compliance costs dominate in explaining the observed responses. 9

In addition, if decreased compliance costs reduce the observed excess mass, we should find that $\hat{b}^{K}>\hat{b}^{C}$. If compliance costs induce no changes, we should observe similar responses before and after the change in compliance costs. Overall, mutually consistent results from both the changes in the tax rate and compliance costs over time would give us straightforward and convincing evidence on the determinants of the observed response.

\subsection{Empirical estimation}

Following the earlier bunching literature (Chetty et al. 2011; Kleven and Waseem 2013), the counterfactual density is estimated by fitting a flexible polynomial function to the observed distribution, excluding an area around $s^{*}$ from the observed distribution. First, we re-center income in terms of $s^{*}$, and group firms into small sales bins of 100 euros. We then estimate a counterfactual density by regressing the following equation and excluding the region around the threshold $\left[s_{L}, s_{H}\right]$ from the regression

$$
c_{j}=\sum_{i=0}^{p} \beta_{i}\left(s_{j}\right)^{i}+\sum_{i=s_{L}}^{s_{H}} \eta_{i} \cdot \mathbf{1}\left(s_{j}=i\right)+\varepsilon_{j}
$$

where $c_{j}$ is the count of firms in bin $j$, and $s_{j}$ denotes the sales level in bin $j$. The order of the polynomial is denoted by $p$. Thus the fitted values for the counterfactual density are given by $\hat{c}_{j}=\sum_{i=0}^{p} \beta_{i}\left(s_{j}\right)^{i}$.

The excess bunching is estimated by relating the actual number of firms close to the threshold within $\left(s_{L}, s^{*}\right)$ to the estimated counterfactual density in the same region:

\footnotetext{
${ }^{9}$ For $\hat{b}^{N}=\hat{b}^{K}$ to hold, the following condition needs to hold: $\delta\left(s^{*}\right) \geq(1-z)\left(s^{*}+\triangle s^{N}\right)-T_{K}\left(s^{*}+\triangle s^{N}\right)$. This implies that in order for the marginal buncher firm not to relocate from below the threshold to $\left(s^{*}+\triangle s^{N}\right)$ after the VAT rate reduction, the compliance costs must be equal to or greater than the net value added at $\left(s^{*}+\triangle s^{N}\right)$. Similar hypotheses are also applicable when analyzing different changes in the VAT rate across similar industries, i.e. when comparing the excess mass estimates of hairdressers that experienced a VAT rate reduction with beauty salons that did not face changes in the VAT rate.
} 


$$
\hat{b}\left(s^{*}\right)=\frac{\sum_{i=s_{L}}^{s^{*}}\left(c_{j}-\hat{c}_{j}\right)}{\sum_{i=s_{L}}^{s^{*}} \hat{c}_{j} / N_{j}}
$$

where $N_{j}$ is the number of bins within $\left[s_{L}, s^{*}\right]$.

As in the earlier literature, we determine the lower limit of the excluded region $\left(s_{L}\right)$ based on visual observations of the sales distribution (and conduct robustness analysis to check the sensitivity of the results to this choice). Intuitively, $s_{L}$ represents the point in the sales distribution where the bunching behavior begins, that is, when the density of firms begins to increase. Due to imperfect control and uncertainty about the exact amount of annual sales, it is likely that we do not observe sharp bunching exactly at the threshold but rather a cluster of firms in a region below it.

We follow the approach of Kleven and Waseem (2013) to define the upper limit. We determine $s_{H}$ such that the estimated excess mass $\hat{b}_{E}\left(s^{*}\right)=\left(\sum_{i=s_{L}}^{s^{*}} c_{j}-\hat{c}_{j}\right)$ equals the estimated missing mass above the threshold, $\hat{b}_{M}\left(s^{*}\right)=\left(\sum_{i=s>s^{*}}^{s_{H}} \hat{c}_{j}-c_{j}\right)$. We apply this convergence condition by starting from a small value of $s_{H}$ and increasing it gradually until $\hat{b}_{E}\left(s^{*}\right) \approx \hat{b}_{M}\left(s^{*}\right)$. This definition for $s_{H}$ denotes the upper bound of the excluded range, and thus the lower bound for estimated excess bunching (Kleven and Waseem 2013) 10 This condition states that firms that bunch at the threshold come from the region directly above it, as shown in Panel IV of figure 3 above. Furthermore, this convergence condition defines the marginal buncher firm with sales $s^{*}+\triangle s$.

In addition, we relate the estimated excess bunching to the change in the VAT rate at the threshold to calculate the tax rate elasticity. We relate the sales response of the estimated marginal buncher firm to the change in the remitted VAT caused by exceeding the threshold by $\triangle s$. Following Kleven and Waseem (2013), we calculate the elasticity at the VAT notch using the following quadratic formula: $e_{N} \approx\left(\triangle s / s^{*}\right)^{2} / \triangle t_{N}$, where $\triangle s / s^{*}=\left(s_{H}-s^{*}\right) / s^{*}$ is the relative sales response of the marginal buncher, and $\triangle t_{N}=\left[\left(s^{*}-z s^{*}\right)+\left(\left(\triangle s-s^{*}\right)-\left(z \triangle s-z s^{*}\right)\right)\right] \tau_{n} / \triangle s$ defines the relative increase in VAT payments caused by exceeding the threshold by $\triangle s$. In the VAT kink regime, the elasticity is $e_{K} \approx\left(\triangle s / s^{*}\right)^{2} / \triangle t_{K}$, where $\triangle t_{K}=\left(\left(\triangle s-s^{*}\right)-\left(z \triangle s-z s^{*}\right)\right) \tau_{k} / \triangle s$.

Compared to the VAT notch, the firm needs to remit VAT only for sales above $s^{*}$

\footnotetext{
${ }^{10}$ Kleven and Waseem (2013) apply this convergence condition to estimate the counterfactual density around individual income tax notches in Pakistan. For individual tax rate kink points in Denmark, Chetty et al. (2011) determine the upper limit visually, and then iteratively adjust the whole counterfactual density above the kink point such that it includes the excess mass at the kink. This makes the estimated counterfactual density equal to the observed density. These procedures are intuitively similar, but the convergence method of Kleven and Waseem (2013) typically produces a smaller estimate for excess bunching. In addition, the convergence method provides a more justified approach to define the upper limit of the excluded region when estimating the counterfactual density.
} 
within the VAT kink system. This implies that the implicit marginal tax rate $\left(\triangle t_{N}\right.$, $\left.\triangle t_{K}\right)$ is larger at the VAT notch compared to the VAT kink with a given sales response $\triangle s$. However, as figure 2 above shows, the average VAT rate increases above the VAT kink, implying a smoothly increasing marginal VAT rate. Therefore, $\tau_{k}$ is not constant in practice, as it increases with $\triangle s$ in the VAT relief scheme. We take this into account when calculating the implied elasticity. In addition, we use the bin-level average of the value added of the marginal buncher firm when calculating the implicit VAT rate and the elasticity estimates.

As is customary in the literature, we calculate standard errors for all the estimates using a residual-based bootstrap procedure. We generate a large number of sales distributions by randomly resampling the residuals from equation (1) with replacement, and generate a large number of new estimates of the counterfactual density based on the resampled distributions. The bootstrap procedure takes into account the iterative process to determine $s_{H}$. Based on the bootstrapped counterfactual densities, we evaluate variation in the estimates of interest. The standard errors for each estimate are defined as the standard deviation in the distribution of the estimate.

\section{Data and descriptive statistics}

\subsection{Data}

Our data are from the Finnish Tax Administration and cover the period 2000-2013. The data contain all businesses that operate in Finland, including firms that are registered for VAT and firms that are not included in the VAT register. The data include information on total sales for firms that are below the VAT threshold, as this information is required for income tax purposes. Thus this data enable us to analyze the effect of the VAT threshold on the distribution of sales.

The data include all information needed for tax purposes, such as sales, taxable profits, expenses, assets and the organizational form. In addition, we have data on other relevant firm-level variables, including the number of employees and the industry classification. Also, we can link owner-level variables, such as the personal taxable wage and capital income of the main owner, to the firm-level data. The owner-level data are available from 2002 onward.

In the following analysis, we exclude all firms that operate in sectors that are not subject to VAT, such as financial and insurance activities, letting and operation of dwellings, 
education, and health and social work activities. Since these firms are not liable to register for VAT, it is not relevant to include them in the analysis of behavioral responses to the VAT threshold. In our baseline analysis, we restrict the sample to include only firms with annual sales below 20,000 euros, since these firms can be thought of as being affected by the threshold. Furthermore, we exclude firms that are taxed on an assessment by the Finnish Tax Administration, as tax record information based on assessment does not provide evidence of behavioral choices of firms in response to the VAT threshold. According to the Finnish Tax Administration, the most common reason for assessed taxation is that a firm has not returned its tax forms in time.

\subsection{Characteristics of small firms and their owners}

Table 1 shows the descriptive statistics of small firms (annual sales between 1,500-20,000 euros) and their main owners. From the firm-level statistics (upper panel) we can unsurprisingly observe that most of the firms in our sample do not have any employees, and have relatively low taxable profits, expenses and assets. The relative average value added of these firms is large, indicating that the expense-to-sales ratio is typically small. This also implies that the effort of the entrepreneur is the largest contribution to the value added of the firm. In addition, the high value added relative to sales indicates that the tax incentives created by the VAT threshold are relevant for most small firms and their owners, as they are subject to considerable relative VAT payments if the threshold is exceeded.

The table shows that sole proprietorship is the most common organizational form among small firms in Finland, as almost 70\% of small firms in our sample are sole proprietors. Less than one fifth of the firms in the sample are privately-held corporations, and $9 \%$ are partnership firms. Overall, $90 \%$ of the firms are owned by a single entrepreneur. Furthermore, small firms represent a wide variety of different industries. However, a large share of firms $(36 \%)$ operate in the service sector, which is a typical industry for single-owned firms and sole proprietors.

The lower panel of table 1 describes the owner-level tax record data. Overall, the average total income of the owner (the sum of taxable gross wage and gross capital income) is relatively low, approximately 16,600 euros. However, there is a lot of heterogeneity with respect to the income level of the owner. Over $50 \%$ of the owners in our sample have very low personal taxable income (below 10,000 euros). Approximately $20 \%$ of the owners have personal income between 10,000-20,000 euros, and roughly $30 \%$ of the owners have 
personal income above 20,000 euros.

In order to more specifically describe the role of the firm in generating income for the entrepreneur, we define owners as 'full-time' entrepreneurs if the annual sales of the firm are larger than the total income of the owner. Most of the owners fulfill our suggestive definition of a full-time entrepreneur, as over $50 \%$ of all main owners in our sample have more annual sales in their firm than they have total personal gross income. Also, 'fulltime' owners are distributed equally across genders. Therefore, the descriptive statistics suggest that part-time businesses do not comprise the majority of our sample, and despite the relatively low level of sales, many small firms are the main source of income for their owner.

Overall, potential heterogeneous responses to the VAT threshold could be important in terms of interpreting the results. For example, the implications of behavioral responses could be different if only side businesses respond to the threshold. In Sections 4.1 and 4.4. we study responses to the VAT threshold separately for different types of firms and owners. 


\begin{tabular}{|c|c|c|c|c|c|c|c|}
\hline & \multicolumn{7}{|c|}{ Firm-level statistics $(\mathrm{n}=713,249)$} \\
\hline & Sales & Expenses* & Value added ${ }^{+}$ & No. of empl. & Profits & Assets & \\
\hline Mean & 8,883 & 2,196 & 6,691 & 0.157 & 1,596 & 10,309 & \\
\hline \multirow[t]{2}{*}{ sd } & 5,346 & 10,844 & 11,632 & 1.100 & 9,471 & 66,840 & \\
\hline & Sole propri. & Corpor. & Partn. & & & & \\
\hline Mean & 0.688 & 0.226 & 0.085 & & & & \\
\hline \multirow[t]{3}{*}{ sd } & 0.463 & 0.418 & 0.279 & & & & \\
\hline & \multicolumn{7}{|c|}{ By industry^ } \\
\hline & Commerce & Construction & Hospitality & Services & Other & & \\
\hline Mean & 0.156 & 0.079 & 0.109 & 0.360 & 0.298 & & \\
\hline \multirow[t]{3}{*}{ sd } & 0.363 & 0.269 & 0.312 & 0.480 & 0.457 & & \\
\hline & \multicolumn{7}{|c|}{ Owner-level statistics $(n=550,373)^{\otimes}$} \\
\hline & Age & Female & Tot. Inc. $(\mathrm{TI})^{\#}$ & $\mathrm{TI}<10 \mathrm{k}$ & TI 10-20k & $\mathrm{TI}<20-30 \mathrm{k}$ & $\mathrm{TI}>30 \mathrm{k}$ \\
\hline Mean & 47 & 0.456 & 16,605 & 0.522 & 0.188 & 0.118 & 0.173 \\
\hline \multirow[t]{3}{*}{ sd } & 13.6 & 0.498 & 958,784 & 0.500 & 0.391 & 0.322 & 0.378 \\
\hline & Full time $e^{\alpha}$ & \multicolumn{2}{|c|}{ Female } & \multicolumn{2}{|c|}{ Male } & & \\
\hline & & Full time & Part time & Full time & Part time & & \\
\hline Mean & 0.519 & 0.252 & 0.204 & 0.267 & 0.277 & & \\
\hline $\mathrm{sd}$ & 0.500 & 0.434 & 0.403 & 0.442 & 0.448 & & \\
\hline
\end{tabular}

Notes: The sample includes firms with sales between 1,500-20,000 euros per year.

* Information from 2002 onward. +Value added is defined as sales minus expenses.

^Industries are categorized using Statistics Finland's standard Industrial Classification (2008). 'Services' include professional, scientific, technical, administrative, support service, social work and other service activities. Transportation and storage are also included in 'Services'. 'Hospitality' refer to hotels and restaurants. 'Construction' includes construction and real estate activities. 'Commerce' includes wholesale and retail trade, and repair of motor vehicles and motorcycles. The category 'Other' includes agriculture, mining, manufacturing, waste management etc. Households acting as employers and extraterritorial organizations are also included in the 'Other' category.

${ }^{\otimes}$ Owner-level information available from 2002 onward. \#Personal total income $(\mathrm{TI})=$ taxable gross earned income + taxable gross capital income. ${ }^{a}$ Full-time $=$ full-time entrepreneur if personal total income (capital income + earned income) $<$ sales of the firm.

Table 1: Descriptive statistics, 2000-2013

\section{Results}

\subsection{Overall responses}

Figure 4 shows the sales distribution around the VAT threshold for all firms in our estimation sample using pooled data from 2000-2013. The figure plots the observed sales distribution (solid line) and counterfactual distribution (dashed line) relative to the threshold in bins of 100 euros in a range of $+/-$ 7,000 euros from the threshold. The threshold is marked with a dashed vertical line. The excluded region $\left[s_{L}, s_{H}\right]$ in the estimation of the counterfactual is marked with solid vertical lines.

The figure denotes the estimate for the excess mass at the threshold with bootstrapped standard errors, and the estimate for the upper limit of the excluded region, $s_{H}$, which is determined by the iterative process explained above. The upper limit also denotes the sales response of the marginal bunching firm, $\triangle s$. Excess bunching is measured 
by relating the number of firms in the observed sales distribution to the counterfactual density within the region $\left[s_{L}, 0\right]$.

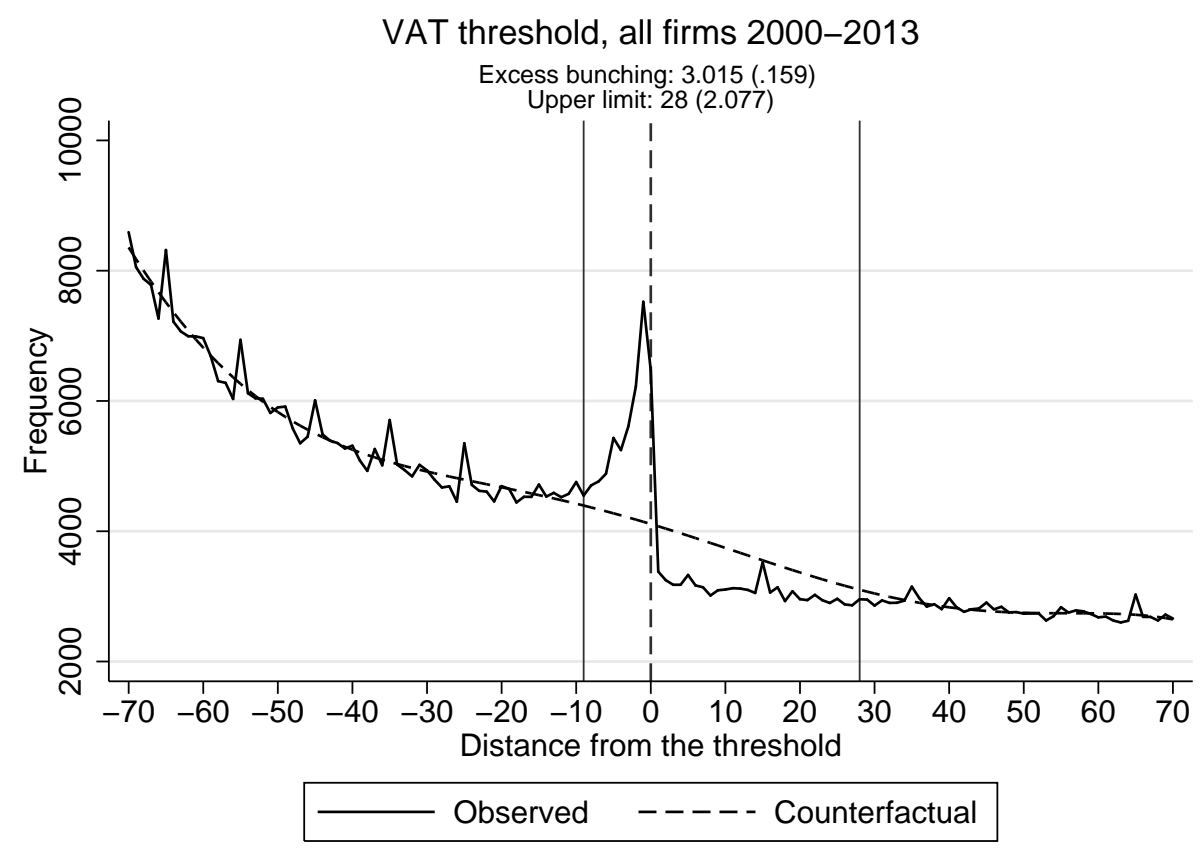

Figure 4: Bunching at the VAT threshold, 2000-2013

Figure 4 shows that the excess bunching is striking. A visually significant proportion of small firms locate themselves just below the VAT threshold. In addition, the estimate of excess bunching (3.0) is notable and strongly statistically significant. These results imply that the VAT threshold clearly affects the reported sales of small firms. The sales distribution is otherwise rather smooth, with the exception of round-number bunching, which can be seen as spikes in the distribution at convenient round numbers such as 5,000 and 10,000 euros. Nevertheless, bunching is much more evident below the VAT threshold than at any of the round numbers, implying apparent behavioral responses to the threshold.

In our baseline analysis, the lower limit of the excluded range is -9 , and the counterfactual density is estimated using a 7th-order polynomial function. Table A1 in the appendix shows the results when we vary these choices. Overall, the conclusion of distinctive excess bunching is robust to different choices. Varying the order of the polynomial from 4 to 10 provides statistically similar results. Decreasing the lower limit from -4 to -15 increases the excess bunching estimate, but estimates using smaller values than -9 provide statistically similar results. As an additional robustness check, we follow Kleven and Waseem (2013) and estimate the counterfactual density taking round-number bunch- 
ing into account, but this does not affect the excess bunching estimate in a significant manner (see figure A1 in the appendix).

Table 2 shows the excess bunching estimates separately for different types of owners and firms. The main observation is that we find significant excess mass estimates and observe visually clear bunching in all subgroups. This indicates that the overall response is not driven by certain groups of firms and owners responding very actively while other groups do not respond at all.

However, we find some differences across different types of owners and firms. First, female owners (excess mass 4.2) appear to bunch more actively than male owners (3.0). In particular, females classified as 'full-time' owners (personal taxable income $<$ sales of the firm) bunch very actively (5.1). One potential explanation for this finding is that household secondary earners, who are typically married women, respond more due to a large inherent tax elasticity found in many previous studies (see e.g. Eissa and Hoynes (2004)). However, our data do not include information on household characteristics, and we are therefore unable to analyze this issue more thoroughly. Nevertheless, we observe clear bunching both for men and high-income entrepreneurs, which implies that the overall effect appears not be in any way limited to secondary earners.

In addition, sole proprietors (3.7) seem to bunch more actively than partnership firms (2.4) and corporations (2.1). The general administrative burden is typically smaller for a sole proprietor compared to corporations and partnership firms. For example, only sole proprietors are entitled to use single-entry bookkeeping. However, VAT regulations and VAT reporting do not differ between organizational forms, which implies that firms with different organizational forms face similar incentives not to exceed the VAT threshold. In addition, firms in the service industry bunch more actively than others, but the bunching is significant in all industry categories, and thus the results are not driven only by certain industries.

Furthermore, we divide firms into quartiles based on their expense-to-sales ratios. This ratio approximates the value added of the firm, and thus describes the variation in remitted VAT at the threshold between different firms. However, this classification does not provide exogenous variation in terms of tax incentives, as many other factors that could affect firm responses also play a role in the composition of the sales and expenses of a firm. For example, it could be more straightforward for firms operating in sectors with low expenses (such as personal services) to adjust their annual sales, regardless of the size of the incentive. Also, firms with large expenses are more likely to voluntarily register for 
VAT, which significantly decreases the incentives to respond to the threshold 11 Table 2 shows that firms with smaller expense-to-sales ratios bunch more actively than others. Nevertheless, firms with large relative expenses also respond to the threshold, but to a significantly lesser extent.

Finally, many of the observed firm and owner-level characteristics are correlated with each other. For example, women have, on average, lower personal total income $(11,400$ euros) in our estimation sample, and over $90 \%$ of female-owned firms are sole proprietors. Also, it is likely that firms with smaller expense-to-sales ratios, such as firms operating in the service sector, have more annual transactions than other similar-sized firms. This means that both the compliance costs of VAT reporting and the implied tax incentives are larger for these firms. Therefore, we are not in general able to distinguish which of these various characteristics or incentives fully explain the greater excess bunching by various groups. In the next subchapter, we utilize variation in tax incentives and compliance costs over time to study the mechanisms behind the observed response.

\begin{tabular}{|c|c|c|c|c|c|}
\hline \multicolumn{6}{|c|}{ Owner-level characteristics } \\
\hline & Women & Men & Full time & Part time & \\
\hline Excess bunching & 4.214 & 3.010 & 4.378 & 2.546 & \\
\hline \multirow[t]{3}{*}{ Std. error } & $(0.140)$ & $(0.146)$ & $(0.133)$ & $(0.138)$ & \\
\hline & \multicolumn{2}{|c|}{ Women } & \multicolumn{2}{|c|}{ Men } & \\
\hline & Full time & Part time & Full time & Part time & \\
\hline Excess bunching & 5.096 & 2.559 & 3.423 & 2.341 & \\
\hline \multirow[t]{2}{*}{ Std. error } & $(0.153)$ & $(0.136)$ & $(0.156)$ & $(0.155)$ & \\
\hline & Total inc. $<10 \mathrm{k}$ & Total inc. $10-20 \mathrm{k}$ & Total inc.20-30k & Total inc. $>30 \mathrm{k}$ & \\
\hline Excess bunching & 4.198 & 2.643 & 2.221 & 2.966 & \\
\hline Std. error & $(0.131)$ & $(0.156)$ & $(0.189)$ & $(0.166)$ & \\
\hline \multicolumn{6}{|c|}{ Firm-level characteristics } \\
\hline & \multicolumn{3}{|c|}{ By organizational form } & & \\
\hline & Sole propr. & Partners. & Corpor. & & \\
\hline Excess bunching & 3.690 & 2.365 & 2.121 & & \\
\hline \multirow[t]{3}{*}{ Std. error } & $(0.121)$ & $(0.200)$ & $(0.229)$ & & \\
\hline & \multicolumn{5}{|c|}{ By industry classifications } \\
\hline & Services & Hospitality & Commerce & Construction & Other \\
\hline Excess bunching & 3.603 & 3.158 & 2.424 & 2.888 & 2.574 \\
\hline \multirow[t]{3}{*}{ Std. error } & $(0.208)$ & $(0.167)$ & $(0.127)$ & $(0.194)$ & $(0.159)$ \\
\hline & \multicolumn{4}{|c|}{ By input/sales ratios } & \\
\hline & 1st quartile & 2nd quartile & 3rd quartile & 4th quartile & \\
\hline Excess bunching & 4.703 & 2.718 & 1.665 & 1.001 & \\
\hline Std. error & $(0.239)$ & $(0.165)$ & $(0.134)$ & $(0.107)$ & \\
\hline
\end{tabular}

Table 2: Excess bunching estimates for different types of owners and firms, 2000-2013

\footnotetext{
${ }^{11}$ For example, in 2009, 34\% of firms below the threshold were voluntarily registered for VAT in the first expense/sales quartile, whereas the share was $59 \%$ in the fourth quartile.
} 


\subsection{Tax incentives and compliance costs}

\subsubsection{Tax incentives}

To understand the implications of size-based thresholds, it is important to know why firms respond to them. In the case of the VAT threshold, small firms could respond to it both because of tax incentives and compliance costs. From a policy perspective, it is crucial to know whether adjusting tax incentives or compliance costs would affect the distortions caused by the threshold. We begin by studying the role of tax incentives. We utilize the change from the VAT notch system to the VAT kink system. Intuitively, if the VAT rate at the threshold matters, we should find notably less firms bunching below the VAT kink compared to the VAT notch.

Figure 5 shows the sales distributions for all firms around the VAT notch regime in 2000-2003 and the VAT kink regime in 2004-2009. The figure clearly shows that excess bunching at the threshold is significant and similar in size both in the VAT notch and the VAT kink regimes. In particular, there is no significant difference when comparing the extent of the behavioral response in 2000-2003 and 2004-2009. The estimate for the difference of the excess mass estimates between these regimes is small and not significantly different from zero, -0.209 (0.237) 12

These findings indicate that despite the drastic drop in the VAT rate after 2004, we find no significant changes in the behavioral response to the VAT threshold. This implies that factors other than the VAT rate are responsible for the decisions of entrepreneurs.

\footnotetext{
${ }^{12}$ This standard error for the difference in the estimates is calculated as follows: we first estimate a large number of excess mass estimates for both the VAT notch and VAT kink periods using the bootstrap procedure explained in Section 2.5. After each round, we calculate the difference of the excess mass estimates, and then calculate the standard deviation of the average difference to examine whether or not the difference in excess bunching between the regimes is significantly different from zero.
} 

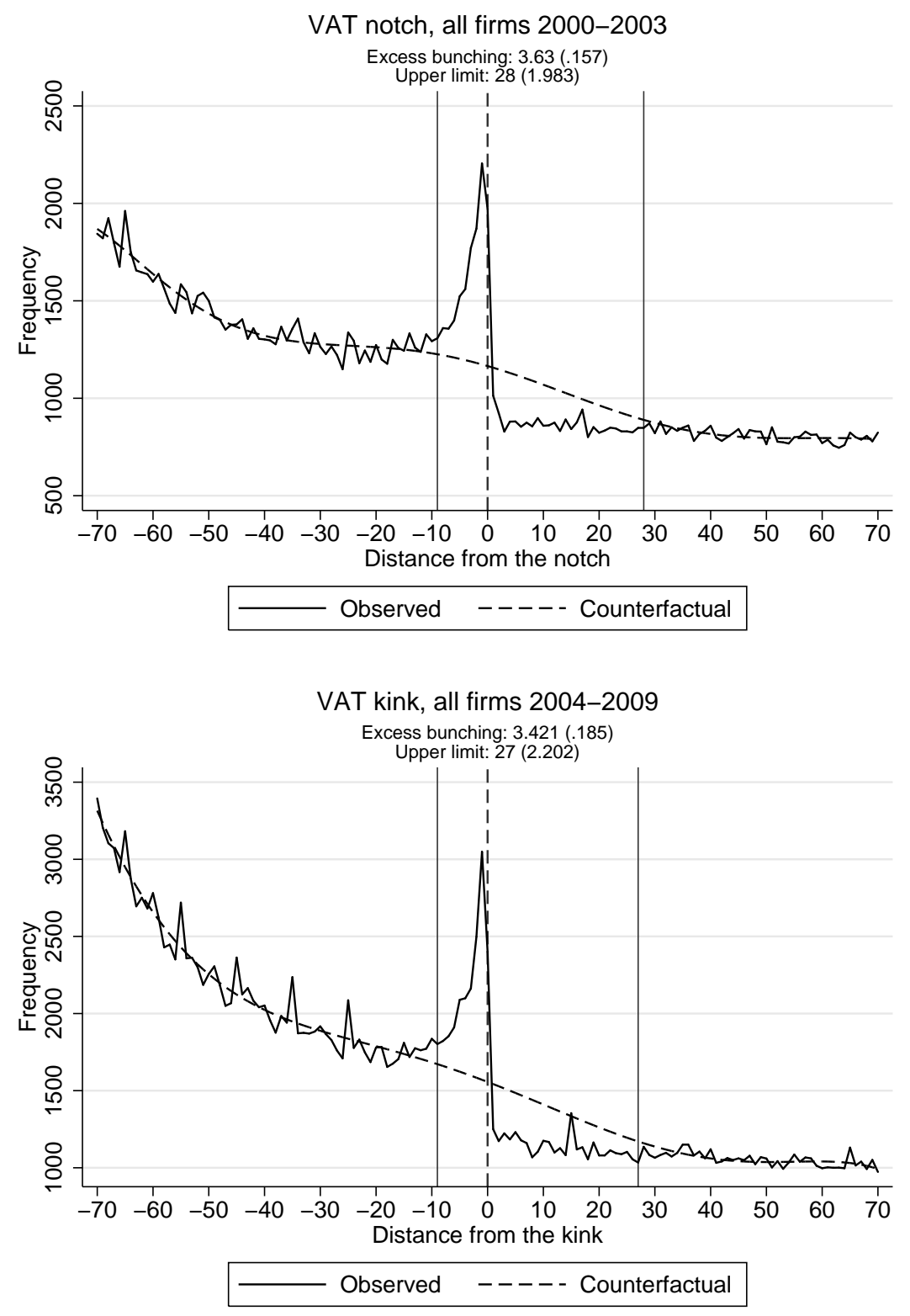

Figure 5: Bunching at the VAT notch (2000-2003) and VAT kink (2004-2009)

To offer further evidence of the effects of tax incentives, we utilize an industry-specific VAT rate reduction. In an experiment with reduced VAT rates in the service industry in Finland, the VAT rate for hairdressers was reduced from $22 \%$ to $8 \%$ in $2007-2011$. Other similar types of services, such as beauty salons, were not subject to the reduced rate. Therefore, if tax incentives drive the response, we should observe a decline in excess bunching for hairdressers in 2007-2011, in comparison to beauty salons.13

\footnotetext{
${ }^{13}$ Kosonen (2015) studies the price and demand effects of this targeted VAT rate reduction for hairdressers using beauty salons as a comparison group. In another reduced VAT rate experiment, the VAT rate for restaurant meals was decreased from $22 \%$ to $13 \%$ in July 2010 in Finland. Harju et al. (2015) study firm-level heterogeneity in price pass-through using the VAT rate reductions for restaurant meals in Finland and Sweden.
} 
Figure 6 shows the sales distributions in 100 euro bins around the VAT threshold for both hairdressers and beauty salons in 2004-2006 and 2007-2009. From the figure, we can observe that hairdressers bunch very actively both before and after the reform (upper graphs), but there is a slight decrease in the estimated excess mass after the reform. However, when compared to beauty salon services, we observe a similar small decrease in excess bunching between the two periods (lower graphs). The estimate for the "difference-in-differences" in excess bunching over time between the two industries is very small and not statistically different from zero $(0.123(1.072)) 14$ This implies that the two sectors do not differ in terms of behavioral responses to the threshold, even though that the VAT rate for hairdressers was nearly $60 \%$ lower in the latter period.

This result provides further evidence that the change in the tax rate does not affect the bunching behavior. It is important to note that potential issues related to understanding the changes in the overall VAT system within the VAT relief reform do not play a role in figure 6. In 2004-2009, the overall VAT system was not changed, apart from the experiment with reduced rates for specific types of services.
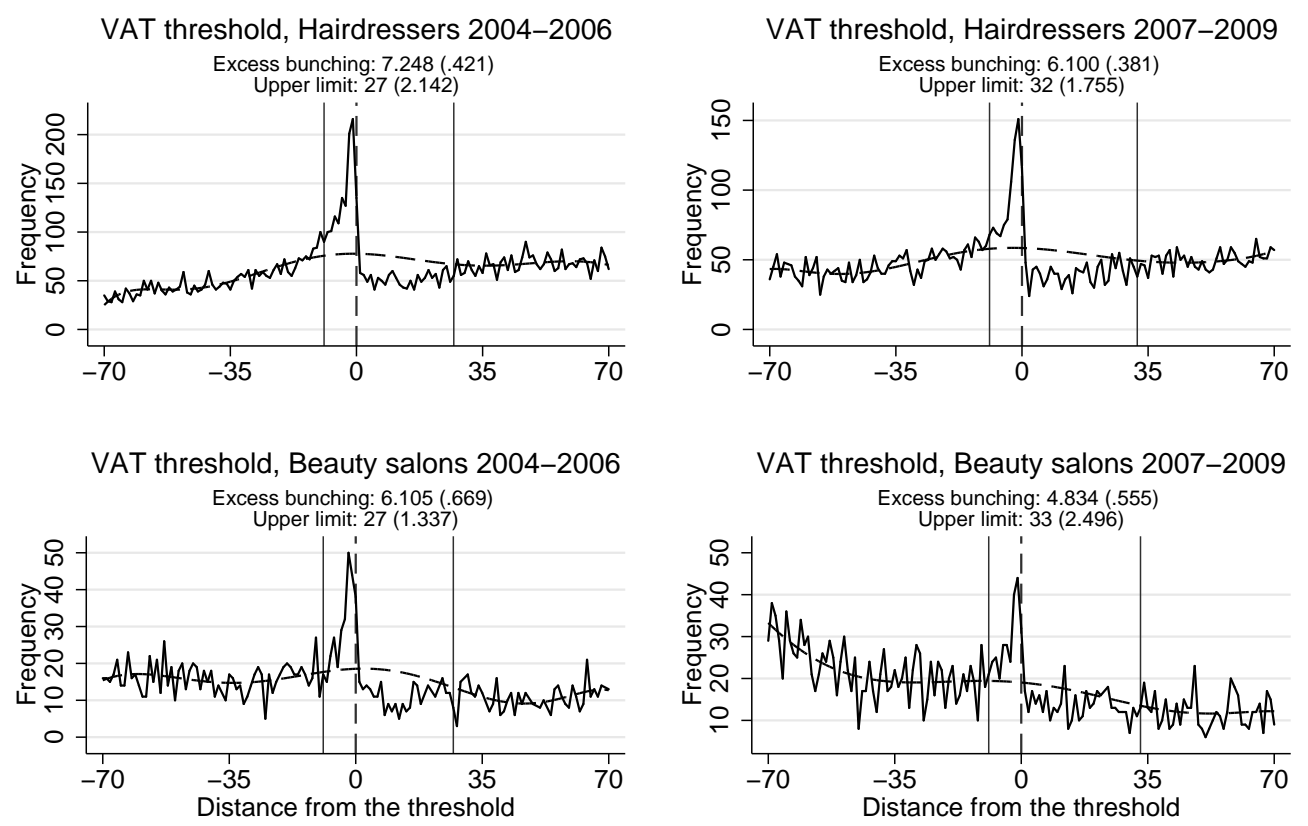

Observed

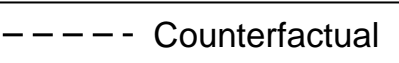

Figure 6: Excess bunching for hairdressers/barbers and beauty salons, 2004-2006 and $2007-2009$

Finally, we study the behavior of voluntarily registered firms. These firms are eligible

\footnotetext{
${ }^{14}$ The standard error for the difference is calculated similarly as described in footnote 12 above.
} 
for full VAT relief from 2004 onward, implying that remitted VAT is zero even for voluntarily registered firms below the threshold. Therefore, as these firms are (voluntarily) subject to the compliance cost of reporting VAT, they only face changes in tax incentives at the threshold. Figure 7 shows that there is no excess bunching for these firms. This result for a selected group of voluntarily registered firms adds our final piece of evidence that tax incentives at the threshold have no significant effect on the behavior of small firms 15

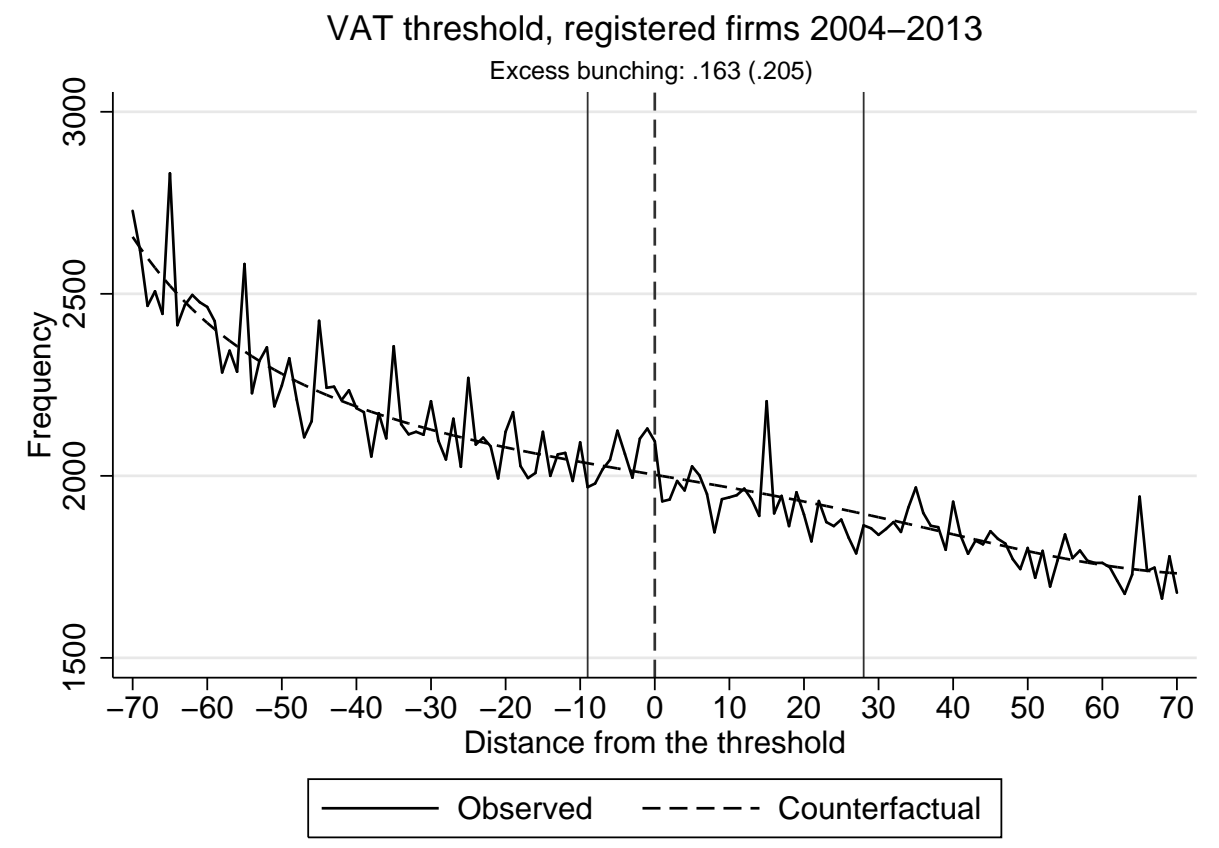

Figure 7: Excess bunching for voluntarily registered firms, 2004-2013

\subsubsection{Compliance costs}

Next we study the effects of the compliance costs of VAT reporting. In 2010, compliance costs were reduced in two ways: First, firms no longer needed to file a separate declaration form to apply for VAT relief. After 2010, just a simple tick in a box in the regular VAT form was required. Second, small firms with annual sales below 25,000 euros are required to file their VAT report annually, in contrast to monthly reporting before 2010.

\footnotetext{
${ }^{15}$ We slightly modify our estimation strategy when estimating excess bunching for voluntarily registered firms. As these firms do not respond to the threshold in a significant manner, we do not observe any drop in the sales distribution above the threshold. Therefore, our baseline iteration method, where the upper limit of the excluded region is defined such that the excess mass equals the missing mass above the threshold, does not converge. Thus we simplify the estimation by using a fixed upper limit of 28 (which is the upper limit in the baseline analysis presented in figure 4). Varying the choice of the fixed upper limit does not change the result in any significant way.
} 
Figure 8 shows the sales distributions and excess mass estimates before (2004-2009) and after (2010-2013) the compliance cost reform. Excess bunching is clearly observable in both periods. However, there is a visible decrease in the excess mass after the reform. The estimate for the difference in excess bunching between these regimes is notable and statistically significant $(-1.345(0.246)){ }^{16}$ These results imply that the reduction in costs related to VAT reporting had a notable effect on behavior, in contrast to changes in tax incentives analyzed above.
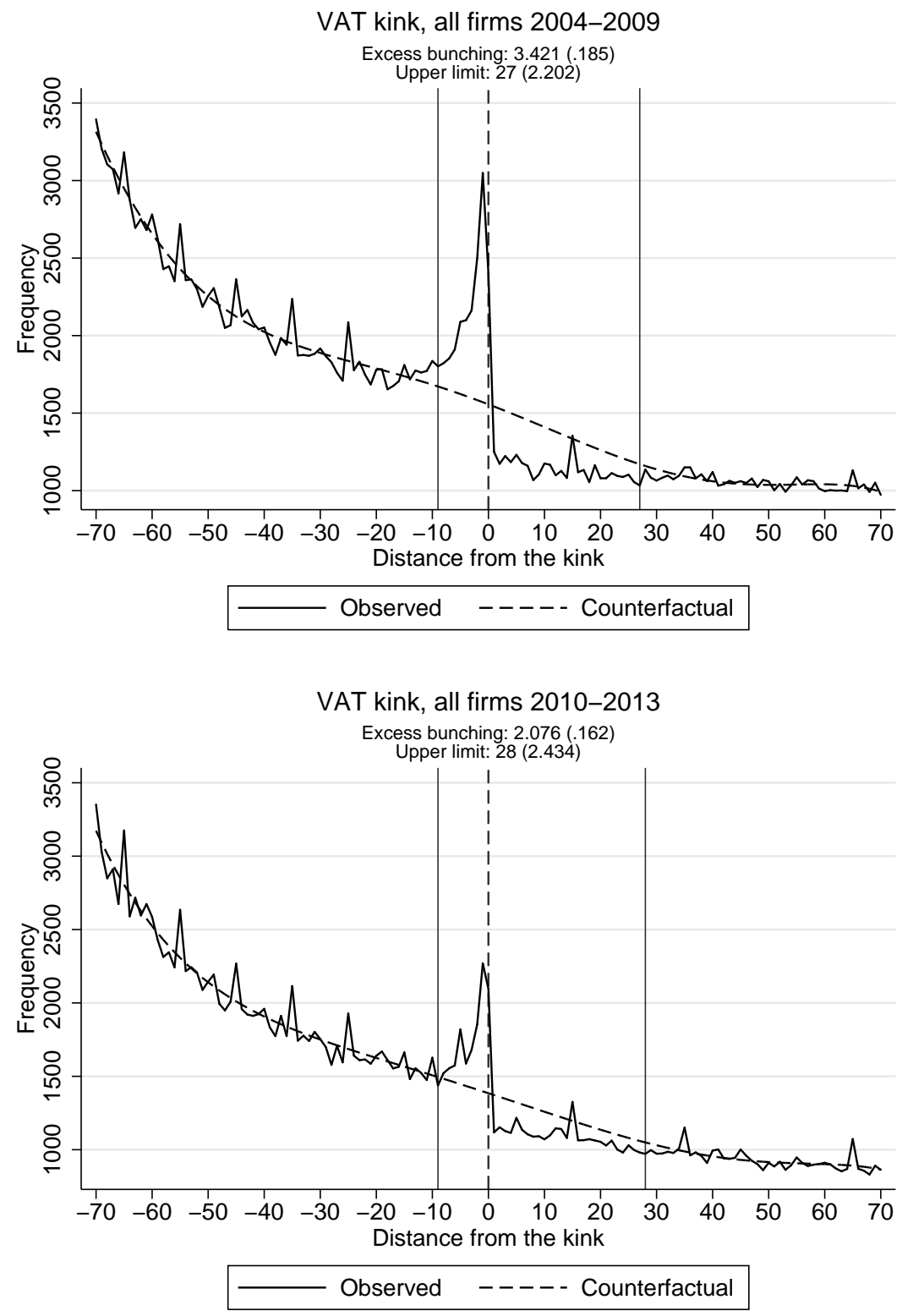

Figure 8: Bunching at the VAT kink before (2004-2009) and after (2010-2013) the change in compliance costs

\footnotetext{
${ }^{16}$ The standard error is calculated similarly as described in footnote 12
} 
The reduction in compliance costs also reduced the costs of voluntary registration. Figure 9 shows the share of voluntarily registered firms below the threshold in 2004-2013. We observe a sharp and distinctive jump in voluntary registration from $45 \%$ to $55 \%$ after 2010. This indicates that the decreased compliance costs increased voluntary registration among small firms. Importantly, voluntarily registered firms were eligible for full VAT relief from 2004 onward, implying that voluntarily registered firms below the threshold only face the compliance costs of VAT reporting.

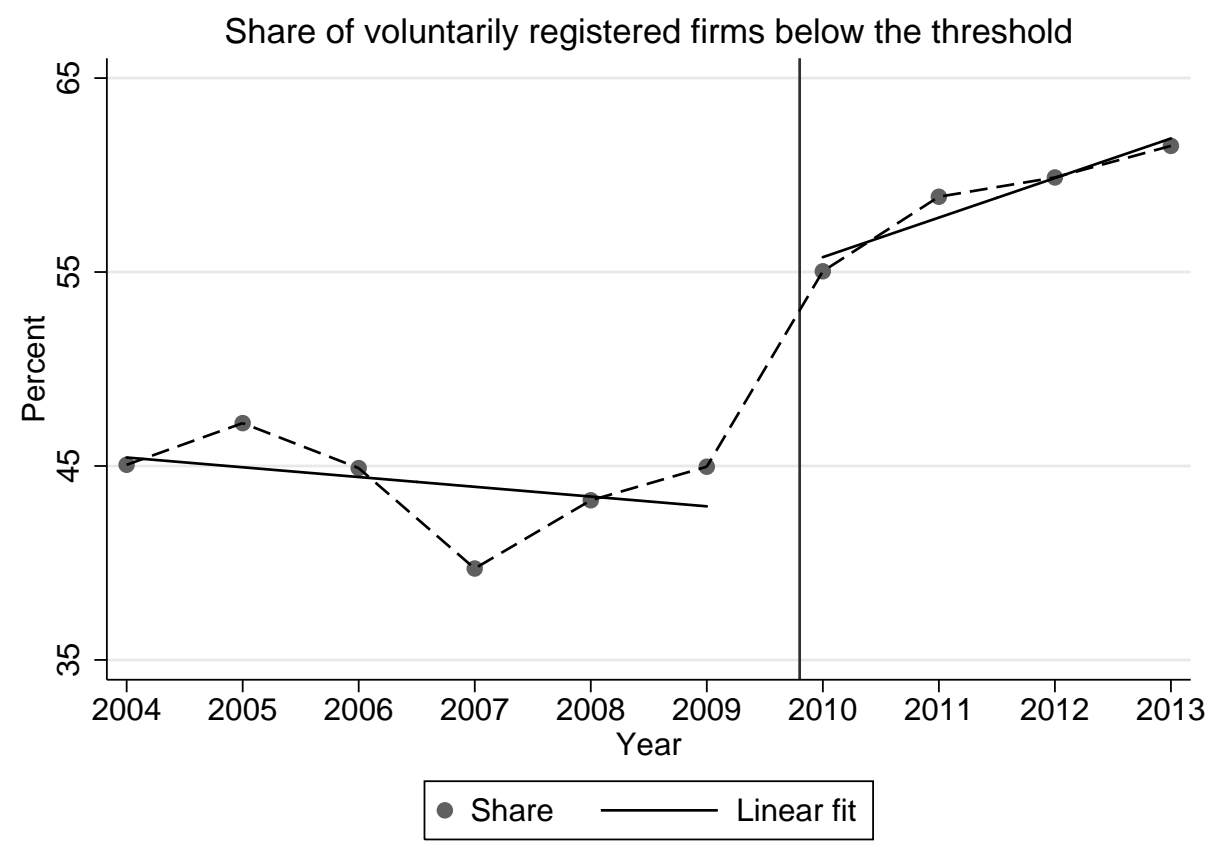

Figure 9: Share of voluntarily registered firms below the threshold, 2004-2013

Cognitive costs related to understanding the VAT rules and regulations could be an important part of compliance costs. One factor that might affect the observed excess bunching and the increase in voluntary registration after 2004 is the transparency and awareness of the VAT relief scheme. Simplifying and clarifying the procedure for applying for the relief in 2010 could thus also contribute to the decrease in observed bunching after the reform.

We do not directly observe awareness of VAT relief among firms and entrepreneurs, but we do observe from the register data whether a firm has applied for the relief. Thus we can characterize the general knowledge of VAT relief by studying how many firms above the threshold apply for the relief, and how this behavior was affected by the 2010 reform. However, the level of this "take-up rate" is likely not to give us accurate information about the actual awareness. Firms might not apply for the relief if the perceived cost 
of applying exceeds the monetary benefit. This is particularly relevant for firms with a large expense-to-sales ratio, as the relative effect of the relief on remitted VAT is smaller for them.

Figure 10 shows the take-up rates of the relief in 2004, 2007, 2011 and 2013. The vertical axis denotes the share of firms that we observed applying for VAT relief. The dashed vertical lines at 20,000 and 22,500 euros denote the end of the relief region in 2004 and after 2005, respectively.

The figure shows that the take-up rate is around 30\% just above the threshold in 2004 and 2007. This suggests that a notable fraction of firms did not apply for the relief. The take-up rate significantly increases to approximately $60 \%$ in 2011 and 2013 . This offers evidence that the awareness of the threshold rules also has an effect. In addition, the figure shows that the share of firms that applied for the relief decreases along with sales, which is reasonable as the monetary relief also gradually decreases at larger sales levels.

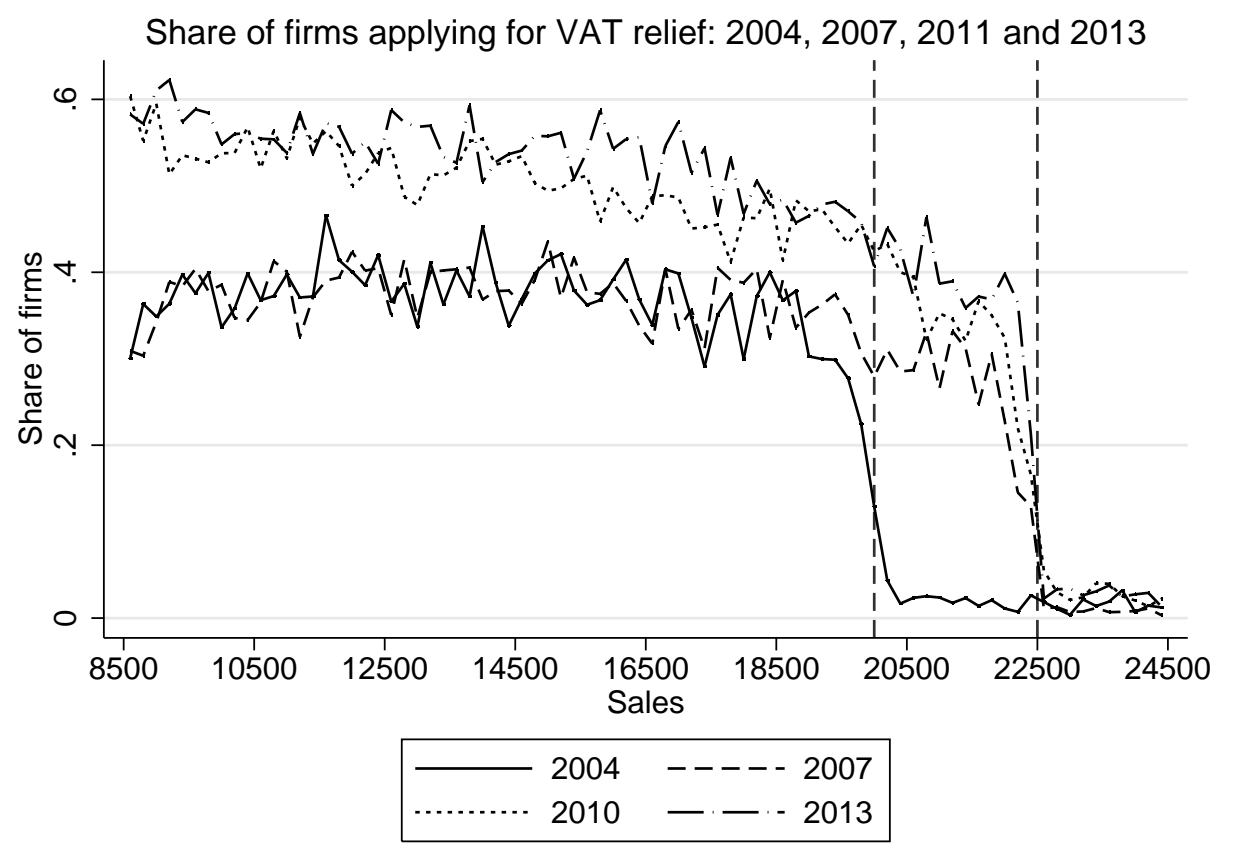

Figure 10: Share of firms applying for VAT relief in 2004, 2007, 2011 and 2013

Finally, we characterize the effect of the costs related to the intensity of VAT reporting. In addition to annual reporting for firms with sales below 25,000 euros, firms with sales between 25,000-50,000 are required to file VAT reports quarterly from 2010 onward, in contrast to monthly reporting before the reform. If the costs related to each VAT report are important, we should find firms bunching below these thresholds of 25,000 and 50,000 euros where the required reporting intensity changes. 
Figure A2 in the appendix shows that there is no excess mass of firms below these sales thresholds. The small and sharp spike exactly at 25,000 euros is likely to be a roundnumber effect, which is also detectable at other convenient round numbers such as 30,000 and 40,000 euros. However, reporting frequency thresholds only describe reporting costs at the intensive margin, i.e. when the VAT threshold is already exceeded and the fixed cost of VAT reporting is materialized. Thus, figure A2 highlights that simply changing the required reporting frequency for firms that are already reporting VAT is not likely to affect firm behavior.

\subsubsection{Summary of the findings on VAT rates and compliance costs}

To summarize, our comprehensive analysis utilizing changes in both the VAT rate and compliance costs over time shows that changes in tax rates do not affect the behavior of small firms, whereas compliance costs appear to be much more important. Figure 11 collects these findings by presenting excess mass estimates and the implied tax elasticity estimates for different years. The elasticity estimates are calculated by relating the sales response of the marginal buncher firm to the change in the remitted VAT, as described in Section 2.5. Following the earlier tax responsiveness literature, this elasticity measure assumes that the change in the VAT rate at the threshold fully causes the behavioral response.

First, we find no changes in excess bunching at the threshold after 2003. We do not observe even a gradual decrease in excess bunching over time, which would be consistent with entrepreneurs gradually learning about the change in tax incentives. In contrast, we observe a sharp drop in excess bunching right after the decrease in compliance costs in 2010 .

Second, we find a clear jump in the tax rate elasticity estimate right after 2004. This is reasonable as the extent of the behavioral response did not change, but the 2004 reform considerably decreased the remitted VAT for the marginal buncher firm. However, it is implausible that the underlying tax rate responsiveness of entrepreneurs would have experienced such a sharp and sudden hike. For the tax rate elasticity estimate to remain constant, we should have observed an excess mass of approximately 0.9 after 2003. However, the observed excess bunching estimate does not decrease at all, and is above 3 both before and after 2004. This evidence strongly supports the hypothesis that the response is driven by compliance costs, and not by the VAT rate. 


\section{Excess bunching and elasticity at the threshold over time}
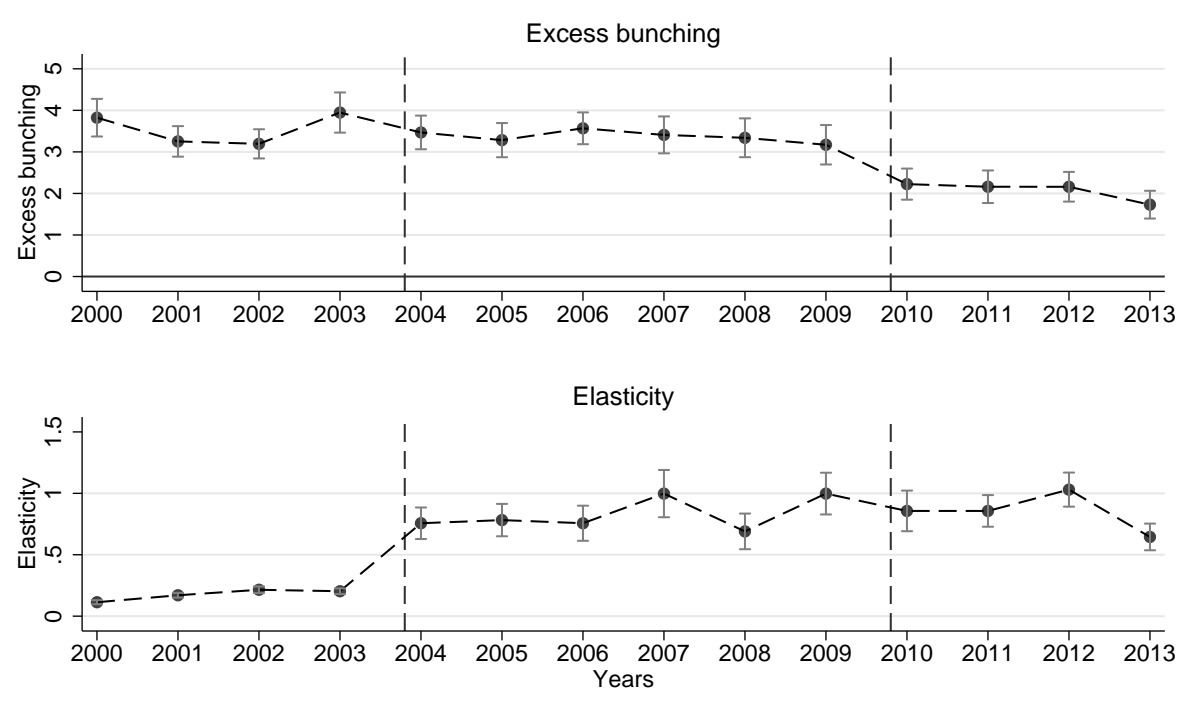

- Estimate $\longmapsto 95 \% \mathrm{Cl}$

Figure 11: Excess bunching and the VAT rate elasticity at the threshold, 2000-2013

Table 3 shows the excess mass estimates in different subgroups in different VAT threshold regimes, and the estimates for the difference in excess bunching within the groups over time. Column (4) of the table shows that the excess mass below the threshold did not decrease in most of the subgroups in a statistically significant manner, not even among firms with lowest expenses relative to sales who presumably had the largest change in tax incentives at the threshold. In contrast, column (5) shows that a reduction in compliance costs significantly reduced bunching in many subgroups. The most distinctive responses occurred among low-income entrepreneurs and service and construction sector firms, implying that the significance of compliance costs is the largest for these groups. We further discuss the implications of the threshold and compliance costs in terms of firm growth in Section 4.4.

Overall, our results highlight the key role of compliance costs in the behavior of small firms. This indicates that the reporting and cognitive costs related to the threshold are the main causes of the distortive effects of this size-based regulation, particularly among low-income entrepreneurs and within the service sector. As a policy conclusion, our results indicate that reducing and simplifying reporting procedures is likely to decrease the welfare costs of size-based rules for small firms. We discuss the implications regarding the optimal level of the VAT threshold in Section 5 . 


\begin{tabular}{|c|c|c|c|c|c|}
\hline \multicolumn{6}{|c|}{ Owner-level characteristics } \\
\hline & (1) & $(2)$ & (3) & $(4)$ & (5) \\
\hline & $2000-2003$ & $2004-2009$ & $2010-2013$ & $(04-09)-(00-03)$ & $(10-13)-(04-09)$ \\
\hline \multicolumn{6}{|l|}{ Women } \\
\hline - Full time & $5.734(0.217)$ & $5.240(0.195)$ & $3.818(0.254)$ & $-0.494(0.288)$ & $-1.422(0.318)$ \\
\hline - Part time & $3.634(0.263)$ & $2.693(0.190)$ & $2.046(0.136)$ & $-0.941(0.323)$ & $-0.647(0.227)$ \\
\hline \multicolumn{6}{|l|}{ Men } \\
\hline - Full time & $3.258(0.179)$ & $4.227(0.222)$ & $-0.717(0.128)$ & $0.969(0.282)$ & $-4.944(0.255)$ \\
\hline - Part time & $2.913(0.205)$ & $2.352(0.187)$ & $2.037(0.167)$ & $-0.561(0.282)$ & $-0.315(0.247)$ \\
\hline Total inc. $<10 \mathrm{k}$ & $4.306(0.144)$ & $4.456(0.173)$ & $-0.431(0.094)$ & $0.150(0.231)$ & $-4.887(0.195)$ \\
\hline Total inc. $10-20 \mathrm{k}$ & $3.546(0.224)$ & $2.427(0.176)$ & $1.745(0.158)$ & $-1.119(0.292)$ & $-0.682(0.239)$ \\
\hline Total inc. $20-30 \mathrm{k}$ & $2.951(0.307)$ & $1.975(0.199)$ & $1.923(0.191)$ & $-0.976(0.359)$ & $-0.052(0.271)$ \\
\hline Total inc. $>30 \mathrm{k}$ & $3.434(0.316)$ & $3.071(0.228)$ & $2.488(0.186)$ & $-0.363(0.392)$ & $-0.583(0.297)$ \\
\hline \multicolumn{6}{|c|}{ Firm-level characteristics } \\
\hline Sole propr. & $4.264(0.151)$ & $3.782(0.155)$ & $2.356(0.127)$ & $-0.482(0.213)$ & $-1.426(0.195)$ \\
\hline Partners. & $3.036(0.361)$ & $2.467(0.250)$ & $1.810(0.199)$ & $-0.569(0.438)$ & $-0.657(0.313)$ \\
\hline Corpor. & $2.338(0.214)$ & $2.312(0.279)$ & $1.425(0.268)$ & $-0.026(0.354)$ & $-0.887(0.394)$ \\
\hline Services & $4.634(0.216)$ & $4.261(0.240)$ & $2.403(0.210)$ & $-0.373(0.318)$ & $-1.858(0.317)$ \\
\hline Hospitality & $3.997(0.268)$ & $3.254(0.214)$ & $2.347(0.206)$ & $-0.743(0.346)$ & $-0.907(0.297)$ \\
\hline Commerce & $2.795(0.198)$ & $2.586(0.144)$ & $1.669(0.182)$ & $-0.209(0.242)$ & $-0.917(0.229)$ \\
\hline Construction & $3.941(0.302)$ & $3.546(0.305)$ & $2.104(0.218)$ & $-0.395(0.440)$ & $-1.442(0.376)$ \\
\hline Other & $3.065(0.168)$ & $2.622(0.200)$ & $1.700(0.200)$ & $-0.443(0.256)$ & $-0.922(0.283)$ \\
\hline \multicolumn{6}{|c|}{ By input/sales ratios } \\
\hline - 1st quartile & $6.879(0.421)$ & $6.500(0.433)$ & $4.512(0.373)$ & $-0.379(0.591)$ & $-1.988(0.572)$ \\
\hline - 2nd quartile & $3.356(0.283)$ & $3.215(0.185)$ & $1.289(0.135)$ & $-0.141(0.345)$ & $-1.926(0.232)$ \\
\hline - 3rd quartile & $1.712(0.260)$ & $1.374(0.138)$ & $0.828(0.133)$ & $-0.338(0.295)$ & $-0.546(0.196)$ \\
\hline - 4th quartile & $1.462(0.267)$ & $0.887(0.097)$ & $0.474(0.117)$ & $-0.575(0.285)$ & $-0.413(0.155)$ \\
\hline
\end{tabular}

Notes: Standard errors in paranthesis. Columns (4) and (5) present the differences in excess mass estimates between 20042009 and 2000-2003, and 2013-2010 and 2004-2009, respectively. The standard errors for the differences in the estimates are calculated as follows: we first estimate a large number of excess mass estimates in both periods using the bootstrap procedure explained in Section 2.5 After each round, we calculate the difference of the excess mass estimates, and then calculate the standard deviation of the average difference.

Table 3: Excess bunching estimates for different types of owners and firms in different tax rate and compliance cost regimes, and estimates for differences in excess bunching between the regimes

Finally, we utilize our results to approximate the magnitude of the compliance cost created by the VAT threshold. To do this, we assume that the entire average response is caused by compliance costs, as indicated by the above results. Therefore, we interpret the response of the marginal buncher to stem from compliance costs only. Using the overall response in 2000-2013, we calculate how much net value added the marginal buncher firm is willing to forgo in order to locate just below the threshold. We find that the compliance costs are approximately 1,600 euros. This estimate is larger than the typical survey-based evaluations of compliance costs for firms, ranging from approximately 600 
to 800 euros (see Crawford et al. (2010)). Our approach adds to this literature by estimating the significance and magnitude of compliance costs for entrepreneurs using quasi-experimental variation and local non-linear estimation methods.

\subsection{Anatomy of the response}

Regardless of whether firms avoid exceeding the VAT threshold because of tax incentives or compliance costs, it is important to know how firms adjust their behavior. In terms of policy implications, it is relevant to know whether firms respond by decreasing output, or by engaging in active avoidance or evasion measures, although responses along all behavioral margins affect tax revenue in a similar manner. However, changes in real economic activity, in this case decreasing the (true) output of the firm, could be more detrimental in terms of welfare, whereas changes through avoidance and evasion might not affect the real allocation of resources with a similar magnitude (see e.g. Slemrod (1992) and Slemrod and Gillitzer (2014) for a discussion of the welfare effects of different types of responses).

To study whether the responses are driven by real responses, avoidance or evasion, we examine how firm-level factors that firms are required to report to the Tax Administration, such as the level of equity, expenses and wages paid to employees, evolve around the VAT threshold. This analysis illustrates the mechanisms related to the observed patterns of responses, rather than providing rigorous evidence of avoidance or evasion. Almunia and Lopez-Rodriguez (2016) use a similar approach when studying the anatomy of the effect of a tax enforcement threshold for large firms in Spain.

How do we predict various firm-level variables to evolve around the VAT threshold? If evasion through underreporting of sales is the main explanation for how firms locate themselves below the threshold, we should find that the level of reported expenses, wages and equity levels are larger just below the threshold. In other words, if sales are systematically underreported, we should observe the bunching firms to be, on average, larger than other firms around the threshold. It is important to note that firms both below and above the threshold have clear incentives to report expenses and wages, as they need to remit taxes on their profits (sales minus expenses and wages). Therefore, in terms of minimizing taxes, there are no incentives to underreport any accrued costs that are tax deductible. Thus in the absence of evasion responses, production factors should develop smoothly around the VAT threshold as the firm's sales increase.

Another explanation for the bunching behavior could be avoidance. One potential 
way to avoid firm-level VAT liability is to set up multiple firms and report the sales of each entity separately such that the threshold is never exceeded. This type of behavior has been previously detected for relatively large firms in Japan (Onji 2009). We test this hypothesis by examining the average number of firms per individual owner around the threshold. If avoidance behavior explains the bunching response, we should find the average number of firms per owner to be significantly larger just below the threshold than above it.

If we do not detect evidence of evasion or avoidance, it suggests that firms respond by reducing real output. However, as in other studies utilizing register-based data and quasi-experimental variation in incentives, we do not observe intentional misreporting of overall business activity, such as operating fully or partly in the black market. Therefore, we are not able to provide conclusive evidence of potential evasion responses ${ }^{17}$

Figure 12 shows the development of firm-level factors around the VAT threshold using pooled data for 2002-2013. In the figure, we plot a local polynomial function with $95 \%$ confidence intervals using a bandwidth of 100 euros to illustrate potential changes around the threshold.

The upper two graphs show that the levels of equity and total wages paid to employees increase smoothly as the sales of the firm increase. In other words, there are no jumps in these variables at the VAT threshold. This implies that firms on both sides of the threshold are equal in size, and gives a first piece of evidence that firms do not locate themselves below the threshold by underreporting their sales.

The lower-left graph in figure 12 shows that the level of expenses jumps significantly just above the threshold, indicating that, on average, firms just below the VAT threshold incur less expenses to achieve a similar level of sales. However, this evidence does not point to active evasion responses below the threshold. In contrast, it rather suggests that firms just below the threshold have higher profit margins and productivity. The lowerright graph in figure 12 also supports this view. On average, firm profits are higher just below the VAT threshold and decrease sharply right above the threshold. As discussed above, this result reflects the earlier finding that firms with smaller expense-to-sales ratios tend to bunch more actively (see table 2). In addition, the result of larger profits below

\footnotetext{
${ }^{17}$ One potential way to evade VAT and to avoid traceable marks on transactions is to accept only cash payments for transactions above the threshold. However, in 2000-2013, the prevalence of cash payments among consumers has reduced significantly. On average, under $1 / 4$ of consumers use cash as their primary method of payment for daily consumer goods in 2006-2013 in Finland (source: Bank of Finland consumer survey, in Finnish only). Therefore, a decision to accept only cash payments presumably reduces business activity, which undermines the potential benefits of evasion.
} 
the threshold is intuitive in the sense that firms just below do not need to remit VAT, and thus have higher after-tax profits than similar firms with equal selling prices above the threshold that are subject to VAT.

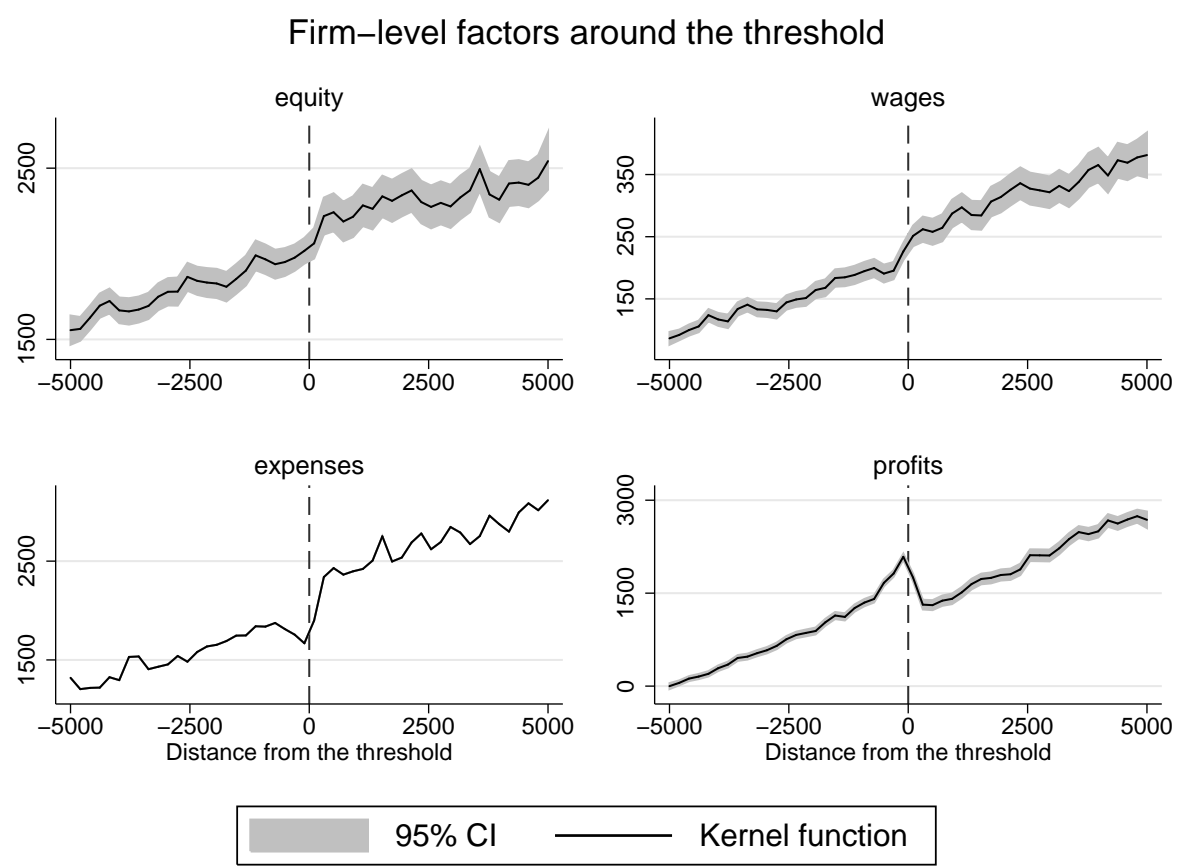

Figure 12: Firm-level factors around the VAT threshold, 2002-2013

In order to more rigorously examine whether or not there are statistically significant differences in reported firm-level factors at the threshold, we utilize the regression discontinuity (RD) method. The RD approach offers us a way to investigate the statistical inferences of potential differences in production factors at the VAT threshold ${ }^{18}$ Table A2 in the appendix shows these results. The level of equity is statistically insignificantly different on both sides of the threshold. For wages, we observe a statistically significant increase at the threshold, but the difference is very small (56 euros). In contrast, the level of expenses is clearly smaller for firms below the threshold compared to firms above it. Consistently, reported profits are also significantly higher for firms just below the threshold. Therefore, these results are in line with the graphical findings.

Figure 13 presents the average number of firms per individual owner around the threshold. The left-hand side of the figure shows that avoidance via multiple firms appears not to explain the observed behavior, as there is no statistically significant jump in the

\footnotetext{
${ }^{18}$ We follow the method presented in Calonico et al. (2014) by implementing a local polynomial RD point estimator with robust confidence intervals. We use a local linear regression with quadratic bias correction, a triangular kernel function to construct the estimator, and mean squared error optimal bandwidths.
} 
number of firms below the threshold. Overall, the average number of firms per owner is very close to one at the threshold. This is driven by the fact that most small firms in Finland are registered as sole proprietors (69\% in our sample). For tax purposes, an entrepreneur cannot set up multiple firms registered as a sole proprietor in the Finnish business tax system.

The right-hand side of figure 13 presents the number of firms per owner when excluding sole proprietors. This graph indicates that the number of firms per owner just below the VAT threshold is larger than above it. This implies that at least some owners appear to set up multiple partnership firms or corporations in order to avoid VAT liability. Nevertheless, this finding does not explain the overall bunching result. Table 2 already showed that excess bunching is evident among all types of firms and owners. In fact, in comparison to sole proprietors, the average excess bunching is somewhat smaller for partnership firms and corporations.

Average number of firms per owner around the threshold

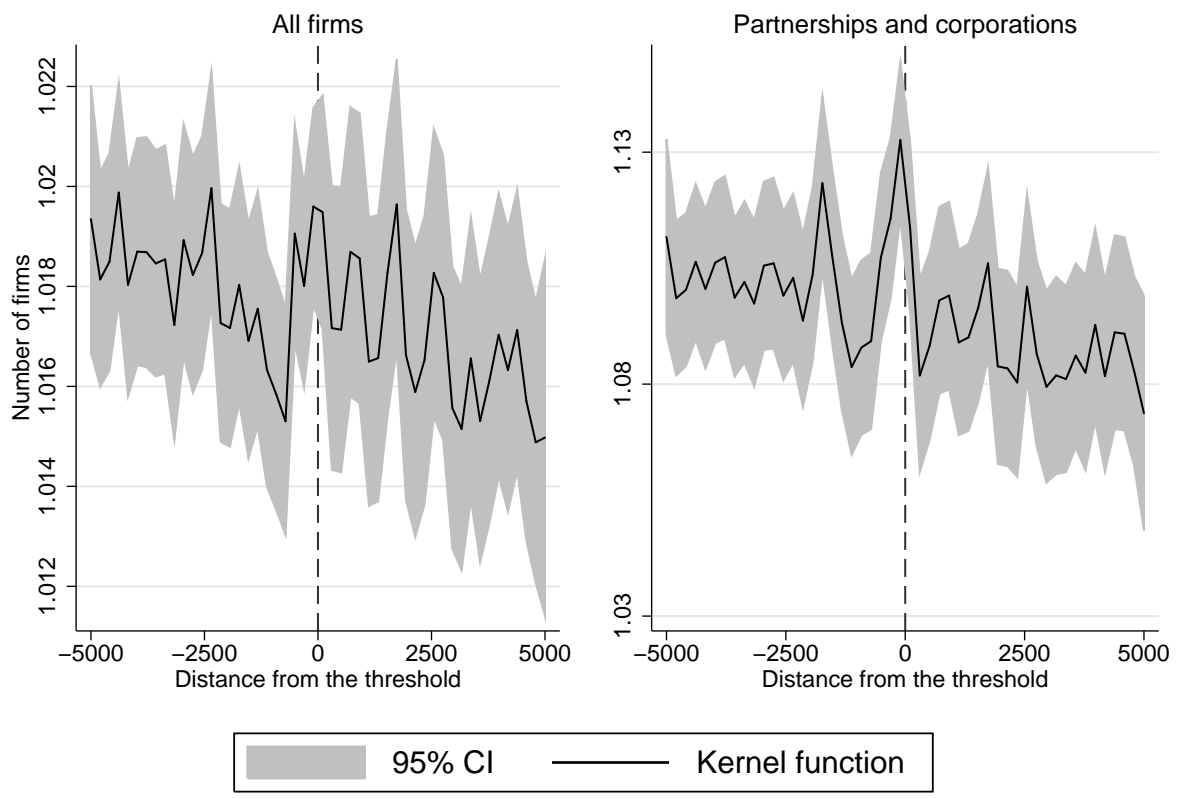

Figure 13: The average number of firms per owner around the VAT threshold, 2000-2013

In summary, we find no evidence that active avoidance and evasion responses explain the observed bunching behavior. This (indirectly) suggests that firms respond to the threshold mainly with a real economic decision, i.e. by reducing output. Previous literature shows that avoidance is an important factor in explaining observed responses to VAT threshold and other size-based rules among larger firms (Onji 2009; Liu and Lockwood 2015; Almunia and Lopez-Rodriguez 2016). However, our findings suggest that small 
firms are not as able to utilize these behavioral margins compared to larger firms, implying that the distortions caused by size-based thresholds could have (significant) welfare consequences among smaller firms.

\subsection{Growth effects}

Size-based thresholds typically create incentives for firms to stay small. This potentially induces negative effects on firm growth. The panel structure of the data allows us to follow firms over time, and thus examine the effects of the VAT threshold on firm growth.

We begin by examining the persistence rates in bunching over time. The persistence rate denotes the probability that a firm remains in the same sales bin from one year to another. Figure 14 presents the persistence rates of firms within different bins of 1,000 euros on both sides of the VAT threshold. The figure clearly shows that the persistence in the bin just below the threshold is notably larger than in other bins close to the threshold. For example, almost $25 \%$ of firms located just below the threshold in the previous year also located in the same bin in the next year (upper-left panel). The persistence rates in other bins close to the threshold are clearly smaller, approximately 10\%. This implies that the threshold significantly hinders the growth of small firms, and creates a barrier for firm growth. Furthermore, the persistence rate just below the threshold seems to be evidently larger than in other bins after multiple years, even after four years (lower-right panel). This further highlights the potentially detrimental growth effects of the VAT threshold. 


\section{Persistence rates}
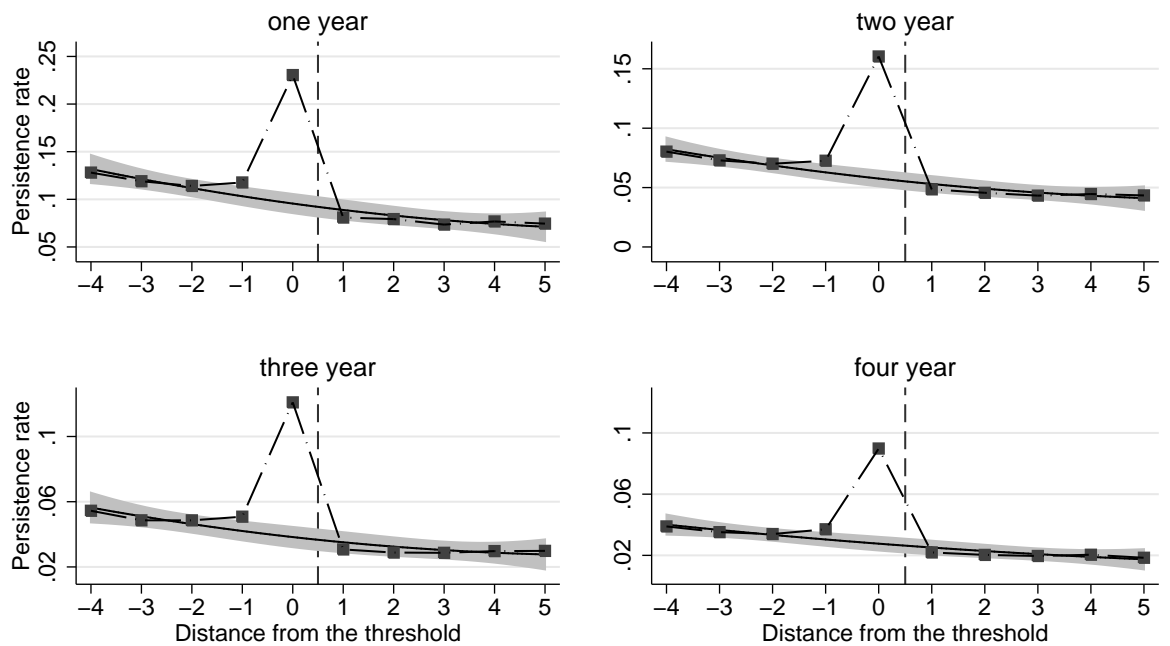

- Estimate $95 \% \mathrm{Cl}$

Figure 14: Persistence rates in different bins around the VAT threshold after one, two, three and four years, 2000-2013

Bunching evidence presented above (tables 2 and 3 ) implies that the behavioral effects of the threshold are largest for low-income entrepreneurs in the service sector, and that these types of firms responded the most to the compliance cost reform. Figure 15 describes the one-year logarithmic growth rates $(t-(t-1))$ of sales conditional on locating in 200 euro sales bins in the base year $t-1$ for owners in different income levels and for firms operating in different sectors. The figure shows that the average growth rate jumps significantly just above the threshold among owners with low personal income (earned + capital income $<10,000$ euros). In contrast, the average growth rates seem to be more stable around the threshold among owners with larger income levels. In addition, the growth effects appear to be larger for firms operating in the service and construction industries, compared to firms in commerce and other sectors. This evidence indicates that the VAT threshold appears to reduce the sales growth rates of firms in service-oriented industries and low-income entrepreneurs, but this lock-in effect is not as significantly present for owners who have, for example, access to significant income outside the firm. Nevertheless, we do observe that high-income owners and firms in other industries also bunch below the threshold, but the threshold does not appear to induce any longer-term distortions to these types of firms. 


\section{Sales growth rates}
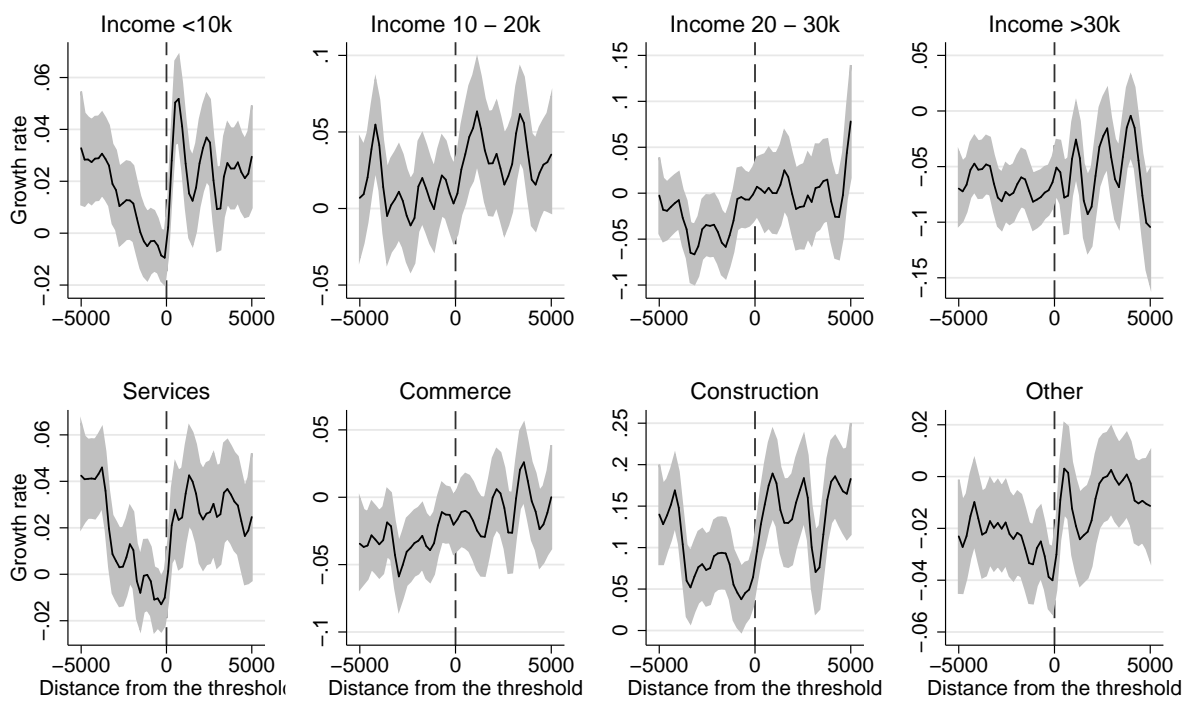

Growth rate

$95 \% \mathrm{Cl}$

Figure 15: Annual sales growth rates for different owners and firms, 2002-2013

Figure 16 describes the growth effects in more detail by characterizing the sales growth rates within the service sector before (2004-2009) and after (2010-2013) the compliance cost reform and across owners with different income levels in 200 euro bins. The lefthand side panels show that before 2010, the annual sales growth rate increased sharply above the threshold among low-income owners, and there is also visible but not as clear of a response for owners with personal income above 10,000 euros. However, the righthand side panels illustrate that the growth effect of the threshold reduced significantly or even vanished after compliance costs were reduced in 2010 in both income groups. This suggests that a reduction in compliance costs effectively decreased the negative implications of the threshold, particularly among low-income service sector entrepreneurs. 
Sales growth rates: Service sector firms
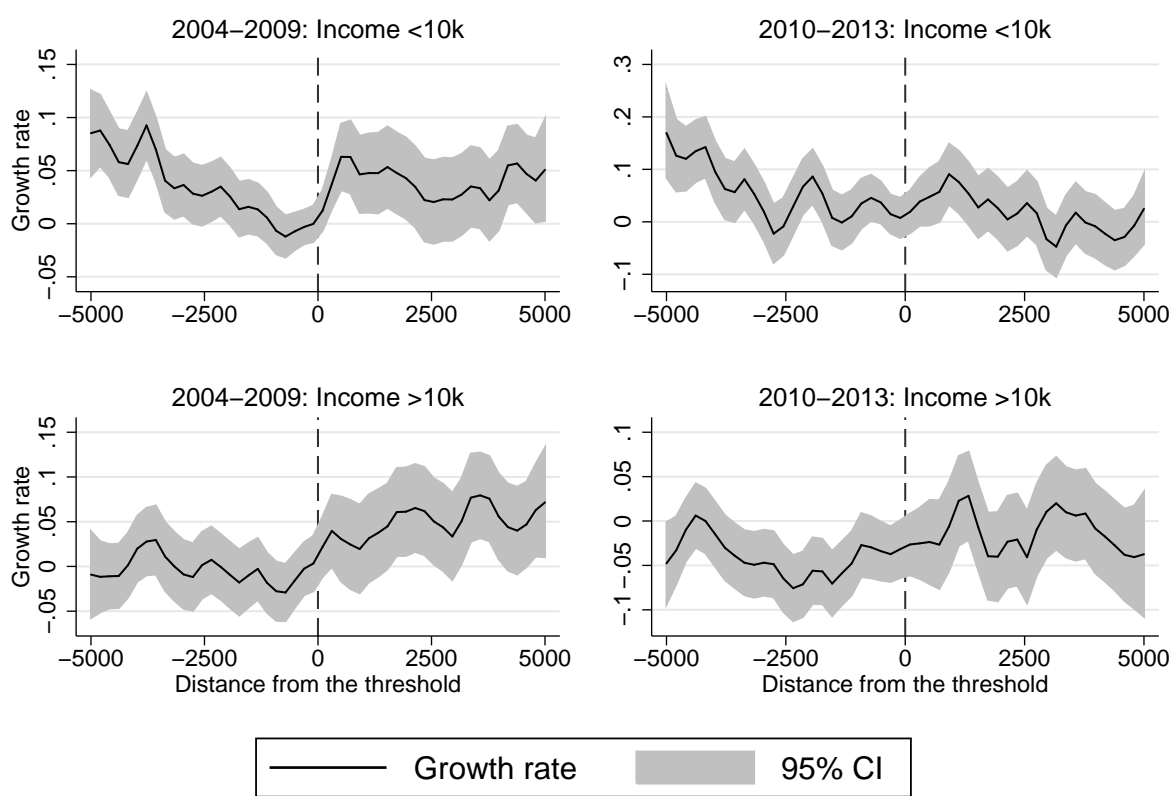

Figure 16: Annual sales growth rates of service sector firms, 2004-2009 and 2010-2013

In addition, we study the growth effects by comparing Finnish firms to similar firms in Sweden, where the VAT threshold is not applied. For Sweden we have data on firms operating in labor-intensive industries in 2005-2013. Thus, in the following analysis, we restrict the data on Finnish firms to include only the same industries within the same period 19

Sweden, as a neighboring country of Finland, represents an intuitive benchmark for analyzing the growth effects of the Finnish threshold. Despite different VAT threshold policies, the VAT systems are otherwise similar in Finland and Sweden, for example, in terms of standard VAT rates and reduced rates for certain industries. Also, Finland and Sweden have similar business tax systems and share similar overall institutions and culture. Therefore, we believe that Swedish firms offer a suitable comparison group for the growth rates of Finnish firms. To support this argument, Harju et al. (2015) find that the overall development of firms in labor-intensive industries is very similar between Finland and Sweden.

Figure 17 shows the kernel density distributions of Finnish and Swedish small firms

\footnotetext{
${ }^{19}$ Data on Swedish firms is used with the permission of the Swedish Tax Agency. Labor-intensive industries cover mainly construction, cleaning and other personal services. In more detail, the data include Swedish and Finnish firms from the following two-digit industry codes: 41-43, 47, 50, 71, 74, 81, 84, 85, 88, 93, 95 and 96. More information on the composition of industry codes is available, for example, on Statistics Finland's website: http://www.stat.fi/meta/luokitukset/toimiala/001-2008/index_en.html (19th of August, 2016).
} 
in 200 euro bins in 2005-2013. As is evident from the figure, Finnish firms bunch clearly at the VAT threshold (vertical solid line in the figure) also in the subsample consisting of firms operating in labor-intensive industries. In contrast, the sales distribution for Swedish firms is smooth, which is consistent with the key finding that the VAT threshold induces notable responses. Second, the relative density of Finnish firms is larger in the whole region below the threshold, and somewhat smaller above it. This gives us a first piece of indicative evidence of the negative growth effects of the threshold when comparing Finland and Sweden.

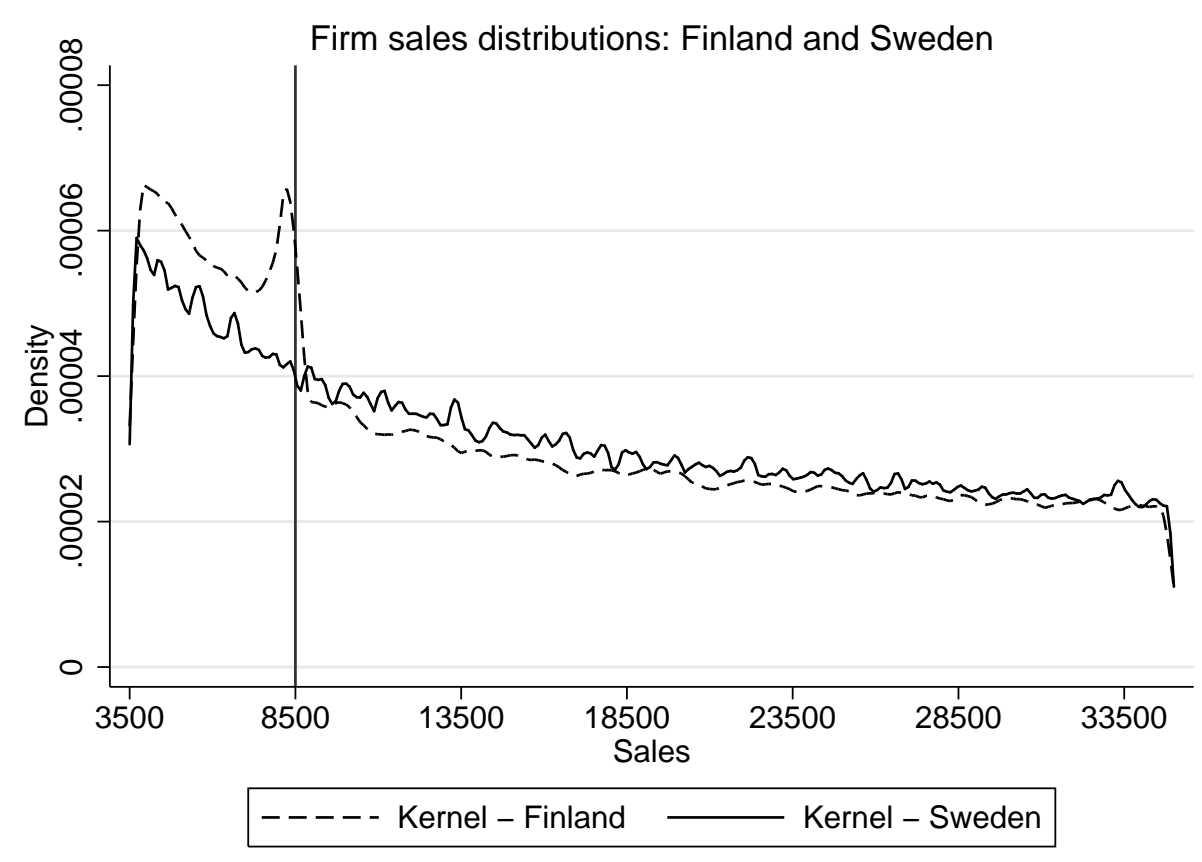

Figure 17: Kernel density sales distributions of Finnish and Swedish firms in laborintensive industries, 2005-2013

Figure 18 shows the average annual growth rates in different parts of the sales distribution (in 200 euro bins) for Finnish and Swedish firms in 2005-2013. The following three points are clearly visible from the figure. First, below the VAT threshold (vertical dashed line), the average growth rate of Finnish firms is approximately zero, while comparable Swedish firms increased their annual sales by $10-15 \%$ on average. Second, above the threshold and below the upper limit of the VAT relief region (vertical dotted line), the growth rates are slightly smaller among Finnish firms compared to Swedish firms. Third, above the upper limit of the VAT relief region, the average growth rates are similar between the countries. These additional descriptive results strongly indicate that the VAT threshold induces negative effects for the growth of small firms in Finland, in comparison to the Swedish system with no such sales-based regulations. 


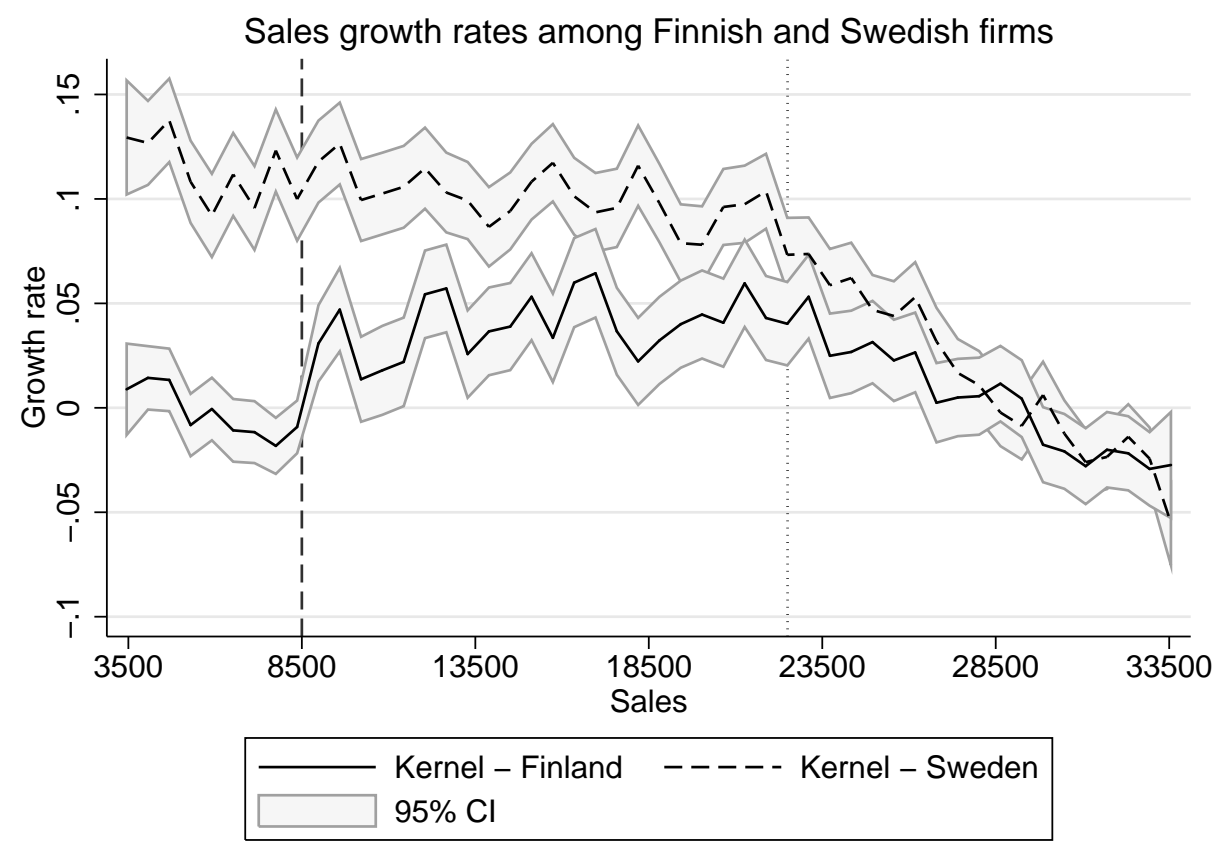

Figure 18: Average annual growth rates in different sales bins for small firms in Finland and Sweden, 2005-2013

The VAT threshold could also affect extensive margin decisions related to the entry and exit of firms, which need to be considered when analyzing the overall distortions caused by this regulation. Figure A3 in the appendix characterizes the effect of the threshold on entry and exit. The figure shows the relative exit rates around the threshold and the distributions of entering firms (at the time the firm/owner is first observed in the data) for firms in labor-intensive industries in both Finland and Sweden. The upper-left graph suggests that the VAT threshold has an effect on exit decisions. It appears that the exit rates are larger for firms above the threshold than for firms below it in Finland. However, the exit rate drops just below the threshold, which is consistent with the above observation of a large number of firms locating themselves below the threshold in many consecutive years. In comparison, the exit rates do not feature such changes in Sweden.

The upper-right graph of figure A3 shows that entering firms also tend to locate themselves just below the threshold. This suggests that the threshold affects the distribution of both new and existing firms. In comparison, the distribution of entering firms declines smoothly with sales in Sweden.

To summarize, the VAT threshold affects the dynamic decisions of firms and distorts the distribution of small firms. We show that bunching behavior is very permanent, as a significant share of firms avoid exceeding the threshold for many consecutive years. This negative growth effect is focused on low-income service sector entrepreneurs rather than, 
for example, owners with significant income outside the firm. Moreover, a comparison between Finnish and Swedish firms that operate in labor-intensive industries supports the overall conclusion that the VAT threshold has considerable effects on growth, highlighting the detrimental dynamic effects of the threshold.

\section{Conclusions}

We find that the VAT threshold for small firms causes significant behavioral responses in Finland. Our results offer compelling evidence that even considerable reductions in the VAT rate do not affect the extent of firms bunching just below the threshold. Instead, we observe that a reduction in compliance costs related to VAT reporting decreased the amount of excess mass at the threshold. This evidence indicates that compliance costs drive the response rather than tax rate changes at the threshold. We also find that bunching behavior is very permanent, implying that the threshold hinders the growth of small firms. We find that the negative growth effects are largest among low-income entrepreneurs in the service sector, but the reduced compliance costs in 2010 significantly decreased the undesirable growth effects. In addition, we find no direct evidence of avoidance or evasion nor that splitting larger firms into smaller entities explains the response, implying that firms decrease their real output to avoid VAT liability.

A vast existing literature focuses on estimating tax rate elasticities in order to recover sufficient statistics on the distortions caused by various taxes. These studies typically ignore the potential effects of compliance costs. Our results highlight that compliance costs induce significant distortions among low-income entrepreneurs, implying that the tax rate elasticity alone is not sufficient when analyzing the welfare loss of the tax system. We find that ignoring compliance costs can considerably overestimate the importance of tax rates. Therefore, if both tax rates and compliance costs are affected by similar (sizebased) rules and thresholds, it is crucial to distinguish between the effects of tax incentives and compliance costs in order to produce consistent policy conclusions.

Our results indicate that reducing and simplifying reporting procedures decreases the welfare costs of size-based rules among small firms, as lowering the costs of VAT registration and reporting reduced behavioral responses to the threshold. In the Finnish case, further avenues for reducing compliance costs include, for example, making the VAT relief system fully automatic (ex officio), and by merging the VAT reporting forms with the annual income tax filing procedure. 
In addition, our results relate to the theoretical literature approximating the optimal VAT threshold. Keen and Mintz (2004) find that the optimal threshold depends on several factors, such as administrative costs, compliance costs, the VAT tax rate, the ratio of value added to sales, and the marginal cost of public funds. Many of these parameters are directly observable, such as the VAT rate and administrative costs. However, compliance costs and the marginal cost of public funds need to be estimated.

Based on our empirical results, we approximate the compliance costs of the VAT threshold for firms to be 1,600 euros. We use this estimate and the formula by Keen and Minz (2004) ${ }^{20}$ to approximate the optimal VAT threshold in Finland. First, we assume that the marginal cost of public funds is 1.3 (following the estimate of Kleven and Kreiner (2006) for Denmark). Then, using a VAT rate of 24\% (standard VAT rate in Finland), a ratio of value added to sales of $70 \%$ (calculated using our baseline sample), and an administrative cost of 320 euros per firm (following Crawford et al. (2010) and assuming that $20 \%$ of compliance costs represent the administrative costs of the tax administration), we approximate the optimal VAT threshold to be 40,000 euros in Finland. This estimate is clearly larger than the current VAT threshold of 10,000 euros.

Therefore, in addition to reducing the compliance costs of firms, the distortive effects of the threshold could be reduced by increasing it. This is intuitive, as the fixed compliance cost is likely to be less significant for larger firms (in relation to sales). However, earlier literature shows that larger firms tend to respond to size-based thresholds by avoidance and/or evasion (see e.g. Onji (2009)), rather than real economic responses. Thus there is likely a tradeoff between reduced negative effects of compliance costs and increased evasion and avoidance responses if the current threshold is increased.

\section{References}

[1] Almunia, M. and Lopez-Rodriguez, D. 2016. Heterogeneous responses to effective tax enforcement: evidence from Spanish firms. Working paper.

[2] Asatryan, Z. and Peichl, A. 2016. Responses of firms to tax, administrative and accounting rules - evidence from Armenia. Unpublished working paper.

\footnotetext{
${ }^{20}$ Keen and Mintz (2004) show that the formula for the optimal VAT threshold is the following: $z^{*}=\frac{\delta A+C}{(\delta-1) \tau N}$, where $\delta$ denotes the marginal cost of public funds, $\tau$ the VAT rate, $N$ the ratio of value added to sales, $A$ administrative costs and $C$ compliance costs.
} 
[3] Bastani, S. and Selin, H. 2014. Bunching and non-bunching at kink points of the Swedish tax schedule. Journal of Public Economics, 109: 36-49.

[4] Benzarti, Y. 2016. How taxing is tax filing? Leaving money on the table because of hassle costs. Working paper.

[5] Besley, T. and Burgess, R. 2004. Can labor regulations hinder economic performance? Evidence from India. Quarterly Journal of Economics, 119(1): 91-134.

[6] Best, M., Brockmeyer, A., Kleven, H., Spinnewijn, J. and Waseem, M. 2015. Production vs. revenue efficiency with limited tax capacity: theory and evidence from Pakistan. Journal of Political Economy, 123(6): 1311-1355.

[7] Boonzaaier, W., Harju, J., Matikka, T. and Pirttilä, J. 2016. How do small firms respond to tax schedule discontinuities? Evidence from South African tax registers. UNU-WIDER Working Paper 36.

[8] Calonico, S., Cattaneo, M. and Titiunik, R. 2014. Robust nonparametric confidence intervals for regression-discontinuity designs. Econometrica, 82(6): 2295-2326.

[9] Carroll, R., Holtz-Eakin, D., Rider, M. and Rosen, H. S. 2001. Personal income taxes and the growth of small firms. In Poterba, J (ed.). Tax Policy and the Economy, Volume 15. MIT Press, 2001.

[10] Chetty, R., Looney, A. and Kroft, K. 2009. Salience and taxation: theory and evidence. American Economic Review, 99(4): 1145-1177.

[11] Chetty, R., Friedman, J., Pistaferri, L. and Olsen, T. 2011. Adjustment costs, firm responses, and micro vs. macro labor supply elasticities: Evidence from Danish tax records. Quarterly Journal of Economics, 126(2): 749-804.

[12] Crawford, I., Keen, M. and Smith, S. 2010. Value added tax and excises. In Adam, S., Besley, T., Blundell, R., Bond, S., Chote, R., Gummie, M., Johnson, P., Myles, G. and Poterba, J. (eds.). Dimensions of tax design: The Mirrlees review, 275-422. Oxford: Oxford University Press, 2010.

[13] Criscuolo, C., Gal, P. N. and Menon, C. 2014. The dynamics of employment growth: new evidence from 18 countries. OECD Science, Technology and Industry Policy Papers, No. 14, OECD Publishing. 
[14] Devereux, M., Liu, L. and Loretz, S. 2014. The elasticity of corporate taxable income: New evidence from UK tax records. American Economic Journal: Economic Policy, 6(2): $19-53$.

[15] Dharmapala, D., Slemrod, J. and Wilson, J. D. 2011. Tax policy and the missing middle: Optimal tax remittance with firm-level administrative costs. Journal of Public Economics, 95(9-10): 1036-1047.

[16] Eissa, N. and Hoynes, H. 2004. Taxes and the labor market participation of married couples: the earned income tax credit. Journal of Public Economics, 88: 1931-1985.

[17] European Commission. 2006a. Council Directive 2006/112/EC.

[18] European Commission. 2006b. Council Directive 2006/18/EC.

[19] Garicano, L., LeLarge, C. and Van Reenen, J. 2016. Firm size distortions and the productivity distribution: evidence from France. American Economic Review, forthcoming.

[20] Gelber, A. M., Jones, D. and Sacks D. W. 2015. Earnings adjustment frictions: evidence from the Social Security Earnings Test. NBER Working Paper 19491.

[21] Gourio, F. and Roys, N. A. 2014. Size-dependent regulations, firm size distribution, and reallocation. Quantitative Economics, 5(2014): 377-416.

[22] Guner, N., Ventura, G. and Yi, X. 2008. Macroeconomic implications of sizedependent policies. Review of Economic Dynamics, 11(4): 721-44.

[23] Haltiwanger, J., Hurst, E., Miranda, J. and Schoar, A. 2016. High growth young firms: contribution to job, output, and productivity growth. In Haltiwanger, J., Hurst, E., Miranda, J. and Schoar, A. (eds.). Measuring Entrepreneurial Businesses: Current Knowledge and Challenges. Forthcoming, NBER Book Series Studies in Income and Wealth, University of Chicago Press.

[24] Harju, J., Kosonen, T. and Nordström-Skans, O. 2015. Firm types, price-setting strategies, and consumption-tax incidence. CESifo Working Paper 5654.

[25] Harju, J. and Matikka, T. 2016. The elasticity of taxable income and income-shifting: what is "real" and what is not? International Tax and Public Finance, 23(4): 640-669. 
[26] Hsieh, C-H. and Klenow, P. J. 2009. Misallocation and manufacturing TFP in China and India. The Quarterly Journal of Economics, 124(4): 1403-1448.

[27] Kanbur, R. and Keen, M. 2014. Thresholds, informality, and partitions of compliance. International Tax and Public Finance, 21(4): 536-559.

[28] Keen, M. and Mintz, J. 2004. The optimal threshold for a value-added tax. Journal of Public Economics, 88: 559-576.

[29] Kleven, H. and Kreiner, C. 2006. The marginal cost of public funds: hours of work vs labor force participation. Journal of Public Economics, 90: 1955-1973.

[30] Kleven, H. and Waseem, M. 2013. Using notches to uncover optimization frictions and structural elasticities: theory and evidence from Pakistan. Quarterly Journal of Economics, 128: 669-723.

[31] Kleven, H. 2015. Bunching. Annual Review of Economics, forthcoming.

[32] Kosonen, T. 2015. More and cheaper haircuts after VAT cut? On the efficiency and incidence of service sector consumption taxes. Journal of Public Economics, 131: $87-100$.

[33] Liu, L. and Lockwood, B. 2015. VAT notches. Oxford University Centre for Business Taxation Working Paper No. 15/06.

[34] Onji, K. 2009. The response of firms to eligibility thresholds: evidence from the Japanese value-added tax. Journal of Public Economics, 93: 766-775.

[35] Saez, E. 2010. Do taxpayers bunch at kink points? American Economic Journal: Economic Policy, 2(3): 180-212.

[36] Saez, E., Slemrod, J. and Giertz, S. 2012. The elasticity of taxable income with respect to marginal tax rates: a critical review. Journal of Economic Literature, 50(1): 3-50.

[37] Slemrod, J. 1992. Do taxes matter? Lessons from the 1980s. American Economic Review Papers and Proceedings, 82(2): 250-256.

[38] Slemrod, J. and Gillitzer, C. 2014. Tax systems. Cambridge: The MIT Press, 2014.

[39] Waseem, M. 2015. Firm responses to value-added tax: Evidence from Pakistan. Unpublished working paper. 
[40] Zervas, G., Proserpio D. and Byers, J. 2016. The rise of the sharing economy: Estimating the impact of Airbnb on the hotel industry. Working Paper.

\section{Appendix}

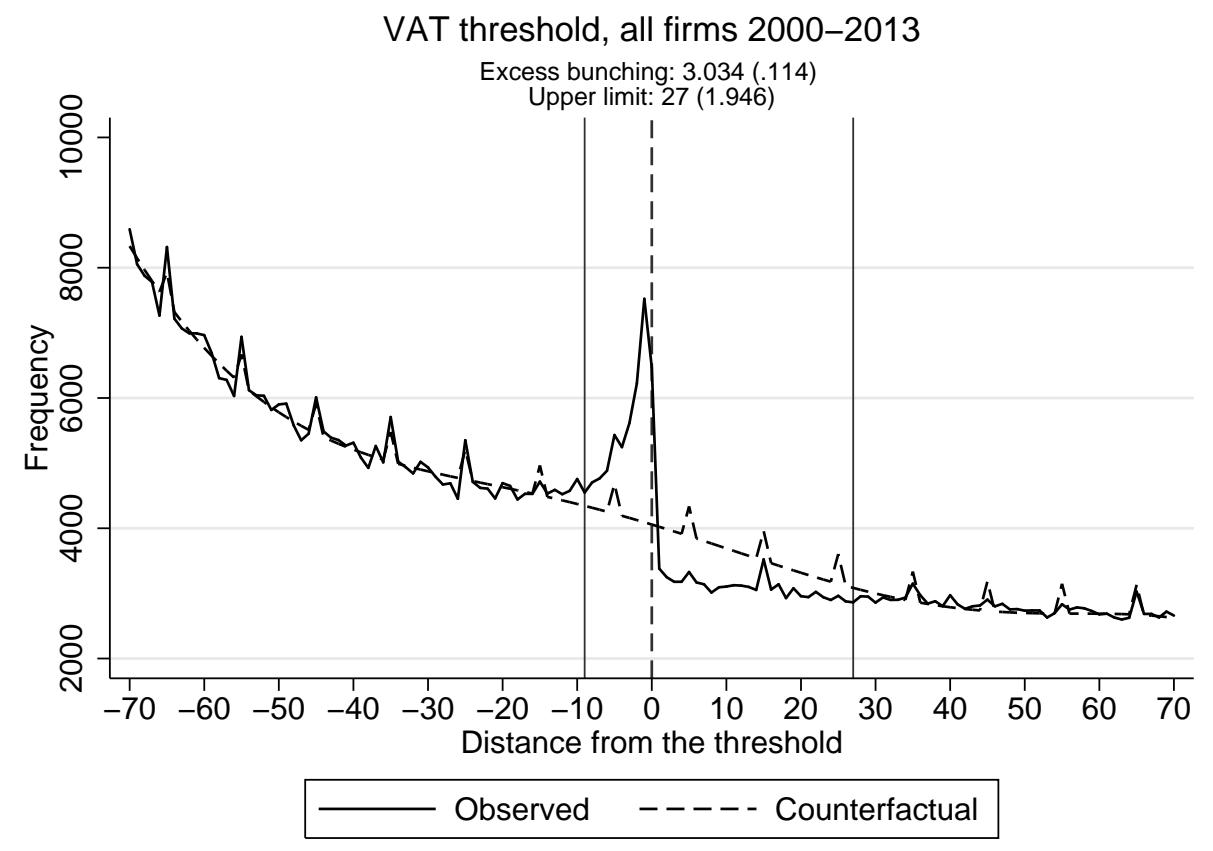

Figure A1: Bunching at the VAT threshold: taking into account round numbers in the estimation of the counterfactual density (100 euro bins), 2000-2013

\begin{tabular}{|c|c|c|c|c|}
\hline \multirow{4}{*}{$\begin{array}{l}\text { Excess bunching } \\
\text { Std. error }\end{array}$} & \multicolumn{4}{|c|}{ Order of polynomial (baseline $=7$ ) } \\
\hline & 4 & 6 & 8 & 10 \\
\hline & 3.201 & 3.022 & 2.840 & 2.607 \\
\hline & $(0.131)$ & $(0.163)$ & $(0.169)$ & $(0.210)$ \\
\hline & \multicolumn{4}{|c|}{ Bunching region $($ baseline $=(-9-0))$} \\
\hline & $-4-0$ & $-6-0$ & $-12-0$ & $-15-0$ \\
\hline Excess bunching & 2.314 & 2.759 & 3.271 & 3.521 \\
\hline Std. error & $(0.082)$ & $(0.112)$ & $(0.226)$ & $(0.292)$ \\
\hline
\end{tabular}

Table A1: Robustness checks: order of the polynomial and the bunching region, 2000-2013 


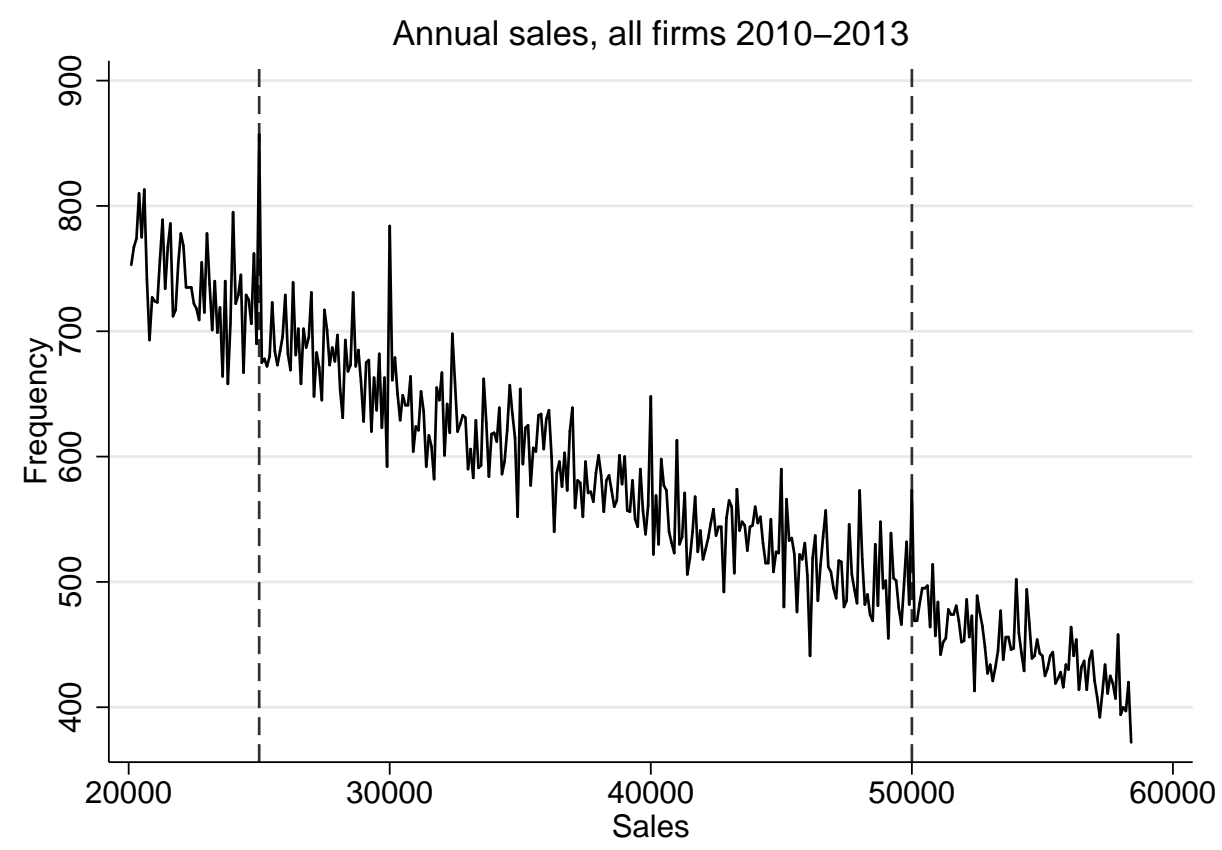

Figure A2: Annual sales of firms and VAT reporting thresholds: 25,000e (quarterly reporting) and 50,000e (monthly), 200 euro bins

\begin{tabular}{lcccc}
\hline VARIABLES & Equity & Wages & Expenses & Profits \\
\cline { 2 - 5 } Estimate & 50.14 & $56.10^{* * *}$ & $1,620^{* * *}$ & $-447.1^{* * *}$ \\
& $(72.98)$ & $(16.44)$ & $(6.145)$ & $(63.73)$ \\
\cline { 2 - 5 } Observations & 98,205 & 84,592 & 14,776 & 63,688 \\
BW Loc. Poly. (h) & 1549 & 1169 & 183 & 860.5 \\
BW Bias (b) & 2888 & 1901 & 456.3 & 2009 \\
\hline Standard errors in parentheses & & \\
$* * * \mathrm{p}<0.01,{ }^{* *} \mathrm{p}<0.05,{ }^{*} \mathrm{p}<0.1$ & & \\
\hline
\end{tabular}

Table A2: Differences in firm-level factors across the threshold calculated using the regression discontinuity approach (following the approach in Calonico et al. (2014)) 

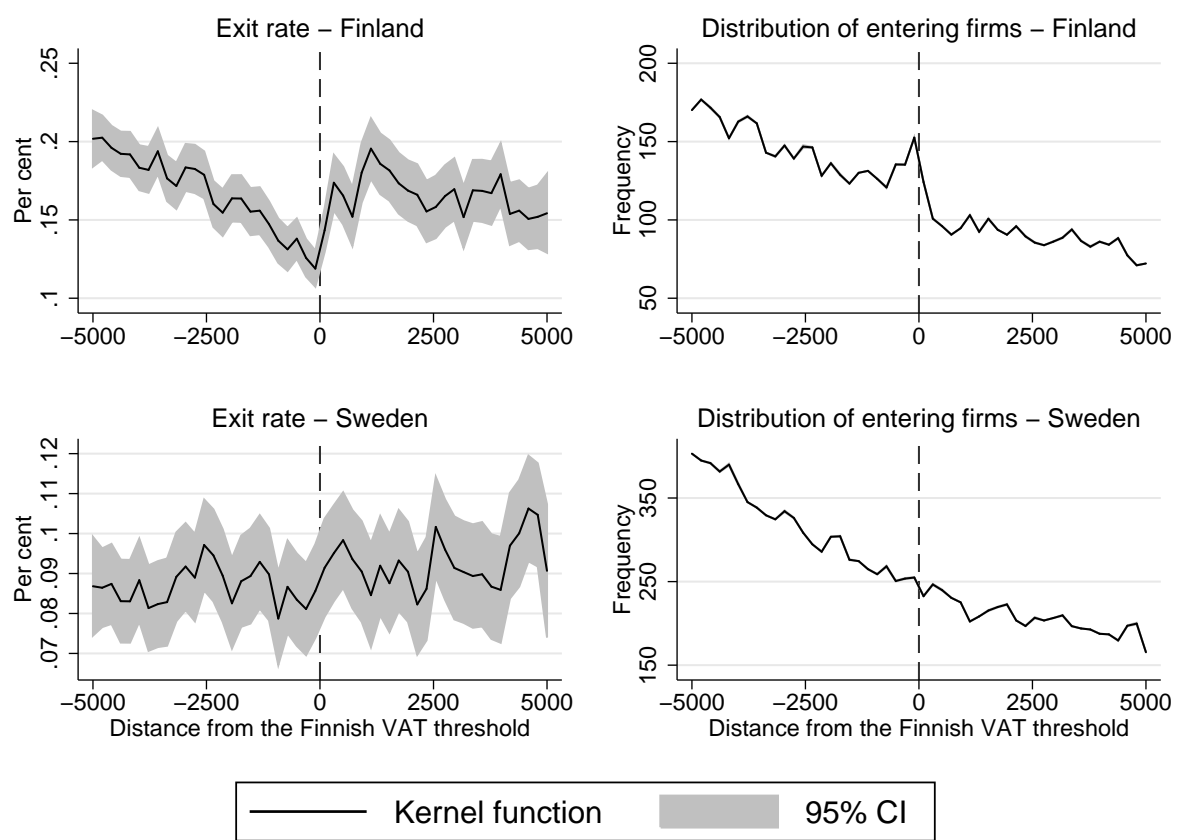

Figure A3: Exit rates and distributions of entering firms in 200 euro bins, firms in laborintensive industries in Finland and Sweden, 2005-2013 